\title{
Mapping and inventorying active rock glaciers in the northern Tien Shan of China using satellite SAR interferometry
}

\author{
Xiaowen Wang ${ }^{1,2}$, Lin Liu ${ }^{1}$, Lin $\mathrm{Zhao}^{3}$, Tonghua $\mathrm{Wu}^{3}$, Zhongqin $\mathrm{Li}^{3}$, and Guoxiang $\mathrm{Liu}^{2}$ \\ ${ }^{1}$ Earth System Science Programme, Faculty of Science, Chinese University of Hong Kong, Hong Kong, China \\ ${ }^{2}$ Department of Surveying and Geo-Informatics, Southwest Jiaotong University, Chengdu, China \\ ${ }^{3}$ Northwest Institute of Eco-Environment and Resources, Chinese Academy of Sciences, Lanzhou, China \\ Correspondence to: Lin Liu (liulin@ cuhk.edu.hk)
}

Received: 30 October 2016 - Discussion started: 8 November 2016

Revised: 13 February 2017 - Accepted: 20 March 2017 - Published: 20 April 2017

\begin{abstract}
Rock glaciers are widespread in the Tien Shan. However, rock glaciers in the Chinese part of the Tien Shan have not been systematically investigated for more than 2 decades. In this study, we propose a new method that combines SAR interferometry and optical images from Google Earth to map active rock glaciers (ARGs) in the northern Tien Shan (NTS) of China. We compiled an inventory that includes 261 ARGs and quantitative information about their locations, geomorphic parameters, and downslope velocities. Our inventory shows that most of the ARGs are morainederived $(69 \%)$ and facing northeast $(56 \%)$. The altitude distribution of ARGs in the western NTS is significantly different from those located in the eastern part. The downslope velocities of the ARGs vary significantly in space, with a maximum of about $114 \mathrm{~cm} \mathrm{yr}^{-1}$ and a mean of about $37 \mathrm{~cm} \mathrm{yr}^{-1}$. Using the ARG locations as a proxy for the extent of alpine permafrost, our inventory suggests that the lowest altitudinal limit for the presence of permafrost in the NTS is about 2500-2800 $\mathrm{m}$, a range determined by the lowest ARG in the entire inventory and by a statistics-based estimation. The successful application of the proposed method would facilitate effective and robust efforts to map rock glaciers over mountain ranges globally. This study provides an important dataset to improve mapping and modeling permafrost occurrence in vast western China.
\end{abstract}

\section{Introduction}

Rock glaciers are lobate or tongue-shaped landforms consisting of mixtures of unconsolidated rock debris and ice in an alpine environment. They are commonly regarded as visible expressions of permafrost presence in periglacial areas (Barsch, 1996; Humlum, 2000; Haeberli et al., 2006; Brenning et al., 2007; Boeckli et al., 2012). Rock glaciers can take several thousand years to develop, so a knowledge of their distribution can provide valuable information about past incidences of permafrost and related climatological characteristics (Humlum, 1998; Konrad et al., 1999; Millar et al., 2015; Sorg et al., 2015). Additionally, due to the potential melting of internal ice in the runoff season, rock glaciers serve as important freshwater reserves for the downstream water use in semiarid regions (Brenning, 2005; Janke et al., 2015).

According to their kinematic status and the presence of internal ice, rock glaciers can be classified into three groups: active, inactive, and relict. Active rock glaciers (ARGs; see the list of abbreviations in the Appendix) typically creep downslope cohesively under gravity by a few centimeters to a few meters per year (Berger et al., 2004; Kääb et al., 2003; Necsoiu et al., 2016). The downslope movement of ARGs may cause mass waste hazards on steep slopes, threatening the sensible infrastructures in some downhill areas (e.g., Schoeneich et al., 2015).

Vertically distributed within a narrow band just above the lower limit of permafrost, active and inactive rock glaciers (collectively termed as "intact" rock glaciers) are indicators of alpine permafrost. Many studies have used active and inactive rock glaciers to map local-scale indicators of permafrost 
occurrence in major mountain ranges such as the European Alps, the Rocky Mountains, the Andes, and the Hindu Kush Himalayan region (e.g., Barsch, 1996; Janke, 2005; Brenning and Trombotto, 2006; Boeckli et al., 2012; Bollmann et al., 2015; Schmid et al., 2015). However, it is difficult to assess the kinematic status of rock glaciers directly (either from the field or remote sensing) and therefore challenging to distinguish active and inactive rock glaciers (Onaca et al., 2016; Sattler et al., 2016). If one only uses ARGs, it would be more accurate and robust to infer the permafrost distribution (Sattler et al., 2016).

It is frequent to use geomorphological features to identify ARGs. Rock glacier movements commonly manifest in viscous flow morphologies on the ground surface, such as the presence and development of ridges, furrows, and steep fronts (Clark et al., 1998; Ikeda and Matsuoka, 2006; Berthling, 2011; Janke et al., 2015). Based on the indications of these geomorphological features, one can map ARGs by visual interpretation through field surveying or aerial/satellite images (Angillieri, 2009; Brenning et al., 2012; Lilleøren et al., 2013; Scotti et al., 2013; Schmid et al., 2015). However, field surveys are usually scarce because most rock glaciers are located in the remote areas and are difficult to access. Because optical images are often affected by clouds and shadows, it is not always feasible to use them to distinguish ARGs from inactive and relict rock glaciers.

In addition to visually interpreting geomorphological features, measuring surface displacements can also be used to identify active rock glaciers. Various terrestrial geodetic techniques such as differential GPS and laser scanning have been used (Lambiel and Delaloye, 2004; Avian et al., 2009; Bollmann et al., 2015). However, these terrestrial techniques are expensive and only offer limited spatial coverage. They have therefore mostly been used in detailed case studies. Multi-temporal optical images have also been used to investigate surface displacements of ARGs through visual interpretation and feature tracking (Gorbunov et al., 1992; Kääb et al., 1997).

In recent years, interferometric synthetic aperture radar (or InSAR) has emerged as a unique technique to investigate the dynamics of rock glaciers (Kenyi and Kaufmann, 2003; Strozzi et al., 2004; Lilleøren et al., 2013; Liu et al., 2013; Barboux et al., 2015; Necsoiu et al., 2016). Compared with optical remote sensing techniques, InSAR provides an allweather imaging capability for measuring ground surface deformation with centimeter to sub-centimeter precision. Thus, the InSAR measurements can be used to determine the kinematic status of rock glaciers (especially their velocities, the upper and lower boundaries), which complement the limitations of optical images (Kenyi and Kaufmann, 2003; Liu et al., 2013). However, the combined use of InSAR measurements and optical images for mapping ARGs in a vast, regional area is still rare. In this study, we proposed an integrative method to identify and map ARGs with improved accuracy, effectiveness, and efficiency by (1) detecting mov- ing landforms using InSAR and (2) interpreting geomorphic features from optical images in Google Earth.

Rock glaciers are abundant in the high mountains of Central Asia and western China, such as the Tien Shan, Hindu Kush Himalayan, Kunlun Shan, and Hengduan Shan. More than 1500 rock glaciers have been inventoried in the Kazakh and Kyrgyz Tien Shan (Gorbunov et al., 1992, 1998). Schmid et al. (2015) compiled an inventory with 702 rock glaciers identified from Google Earth images in the vast Hindu Kush Himalayan region. Using these inventories, recent studies have further discussed the rock glacier-permafrost interactions (Bolch and Gorbunov, 2014; Schmid et al., 2015). However, rock glaciers in western China have not been systematically investigated except for a small number of studies conducted more than 2 decades ago. Based on the interpretation of aerial photos and field surveys, Cui and Zhu (1989) and Zhu (1992) identified hundreds of rock glaciers in the northern Tien Shan (NTS) of China, while Cui (1984) and Li and Yao (1987) identified dozens of them in the Kunlun Shan and the Hengduan Shan, respectively.

The previous studies of rock glaciers in western China mainly focused on their shapes, classification, and topoclimatic conditions. The studies on surface velocities of rock glaciers are very limited except for the field surveys at several specific sites conducted by Cui and Zhu (1989) and Zhu (1992). Additionally, there has not been any discussion on the permafrost distribution in these high mountains in western China based on locations of rock glaciers. In this study, we applied the new integrative method to identify and map the ARGs in the NTS region as an example study area. We determined the geographical locations of ARGs based on the proposed method. Then, we systematically summarized their geomorphic and climatic attributes, as well as their surface velocities. Finally, we inferred the lower limit of permafrost in the NTS from the inventoried ARGs, offering a modern, comprehensive, and rigorous update from the previous field-based estimates by Qiu et al. (1983). We also compared our inventory with the previous studies and existing permafrost maps.

\section{Study area}

The Tien Shan is a major mountain system in Central Asia, with a mean altitude of more than $4000 \mathrm{~m}$ above sea level. The Tien Shan extends $2500 \mathrm{~km}$ by $250-300 \mathrm{~km}$, spanning regions of Uzbekistan, Kyrgyzstan, southeastern Kazakhstan, and the Xinjiang province of China. The Chinese portion of Tien Shan divides Xinjiang into two large basins, the Tarim Basin in the south and the Junggar Basin in the north, with the Gurbantünggüt and the Taklamakan Deserts lying in hinterland basins (Fig. 1). Due to its geographical location and rugged topography, Tien Shan possesses the ideal climatic conditions for the creation and preservation of mountain permafrost. Qiu et al. (1983) estimated that permafrost 
in the Chinese part of the Tien Shan covers approximately $6.3 \times 10^{4} \mathrm{~km}^{2}$. In this study, we focus on the NTS of China $\left(82-87^{\circ} \mathrm{E}, 42-44^{\circ} \mathrm{N}\right)$, a large branch of the Tien Shan striking $\mathrm{N} 20^{\circ} \mathrm{W}$ from northwest to southeast (Fig. 1). We note that some literature also refers to the part of Tien Shan in Kazakhstan and Kyrgyzstan as "northern Tien Shan". If not explicitly stated, "NTS" refers to our study area in China in the remainder of this paper.

The eastern and western parts of the NTS divide along longitude $86^{\circ} \mathrm{E}$ and possess distinct climatic characteristics (Zhu et al., 1992; Zhao et al., 2010). The west is relatively humid and cold. In contrast, the east is dry and cold. There are two long-term meteorological stations in the NTS. The Daxigou meteorological station $\left(86.84^{\circ} \mathrm{E}, 43.11^{\circ} \mathrm{N}\right)$ in the eastern part is at about $3540 \mathrm{~m}$ above sea level. The Snow-cover and Avalanche Research Station (SARS; $84.40^{\circ}$ E, $43.26^{\circ} \mathrm{N}$ ) lies in a valley in the western part of the NTS, at an elevation of about $1776 \mathrm{~m}$. The mean annual air temperature (MAAT) and the mean annual precipitation around the Daxigou station were about $-6^{\circ} \mathrm{C}$ and $405 \mathrm{~mm}$ in $1990-2008$, respectively (Sun et al., 2013). The MAAT near the SARS was about $1.3^{\circ} \mathrm{C}$, falling to $-9.4^{\circ} \mathrm{C}$ at $3580 \mathrm{~m}$. The mean annual precipitation at the SARS was about $830 \mathrm{~mm}$ (Shi et al., 2009). The east-west contrast is also evident in the number and size of mountain glaciers. The west hosts more and larger glaciers than the east.

\section{Methodology}

We identified ARGs and measured their surface velocities by using InSAR and optical images. In this section, we first present the details of the InSAR processing for detecting the moving targets in the interferogram and the rules used to identify ARGs in Google Earth by visually interpreting their geomorphic features (Sect. 3.1). We then describe the method to derive the downslope velocities of the ARGs (Sect. 3.2). Finally, we list and explain the criteria for compiling an inventory that contains the geomorphic and dynamic attributes of the identified ARGs, followed by a description of the uncertainty analysis (Sect. 3.3).

\subsection{Identifying and mapping active rock glaciers}

\subsubsection{Identifying ground movements using SAR interferometry}

The InSAR technique detects the ground movements by exploiting the phase difference between SAR images acquired at different times (Rosen et al., 2000). The phases in the differential interferogram are wrapped within $-\pi$ to $\pi$. One phase cycle corresponds to one-half wavelength (e.g., $11.8 \mathrm{~cm}$ for $\mathrm{L}$ band) of ground displacements along the lineof-sight direction (Rosen et al., 2000; Wang et al., 2015). We used wrapped interferograms rather than unwrapped displacement maps to detect ARGs because wrapped phases in the interferogram show apparent variations visually even if the ground movements are small, for instance at centimeter level.

We used seven orbital paths of L-band ALOS PALSAR images acquired from 2007 to 2009 to cover the entire study area. All images were collected at a radar off-nadir angle of $38.7^{\circ}$ in $\mathrm{HH}$ polarization and have a pixel spacing of $4.7 \mathrm{~m}$ in slant range and $3.2 \mathrm{~m}$ in azimuth. For each orbital path, we used one image pair to form one interferogram. All the PALSAR images we used, except for Path 503, were acquired in summer seasons. To achieve high interferometric coherence, we selected the image pairs with temporal spans of either 46 or 92 days and critical perpendicular baselines smaller than $600 \mathrm{~m}$ for further processing. Table 1 supplies detailed information on the interferometric pairs. With the availability of PALSAR images, we implemented the interferometric processing by using GAMMA software (Wegmüller et al., 1998). The topographic phases were estimated and removed by using the 1 arcsec SRTM digital elevation model data with a spatial resolution of about $30 \mathrm{~m}$. We applied multi-looking operation ( 2 looks in range and 5 looks in azimuth) and filtered interferometric phase using the adaptive Goldstein filter with a window size of 8 by 8 pixels. Finally, we obtained the interferogram maps with a spatial resolution of about $15 \mathrm{~m}$.

However, we were unable to map the ARGs solely based on the phase variations in the interferograms. First, the phase variations can be caused by several kinds of error sources in SAR interferograms such as decorrelation noise, residual topography contribution, and atmospheric delay. The contribution of the topographic error to the interferometric phase is proportional to the perpendicular baseline, the radar slant range, and the radar look angle (Rosen et al., 2000). The maximum perpendicular baseline of the interferograms produced in this study is about $600 \mathrm{~m}$. Adopting the vertical accuracy of the digital elevation model as its nominal value of $16 \mathrm{~m}$ (Farr et al., 2004), we estimated that the residual topographic phase in the InSAR measurements would be about 0.92 radians, corresponding to $1.7 \mathrm{~cm}$. The atmospheric (including tropospheric and ionospheric) effects are generally long wavelength (1-10 km) signals (Hanssen, 2001), which thus can be assumed nearly constant over a specific rock glacier. By using a local reference point just outside each rock glacier (see Sect. 3.2), we effectively removed these large-scale atmospheric errors. Second, the moving targets may correspond to other periglacial landforms such as debris flow, solifluction, and protalus lobes (Scotti et al., 2013). Therefore, we decided to overlay the interferograms on optical satellite images in Google Earth to identify the ARGs by visually interpreting their morphological features.

\subsubsection{Identifying active rock glaciers using Google Earth images}

The Google Earth images covering our study area were acquired by the SPOT satellite with spatial resolution gener- 


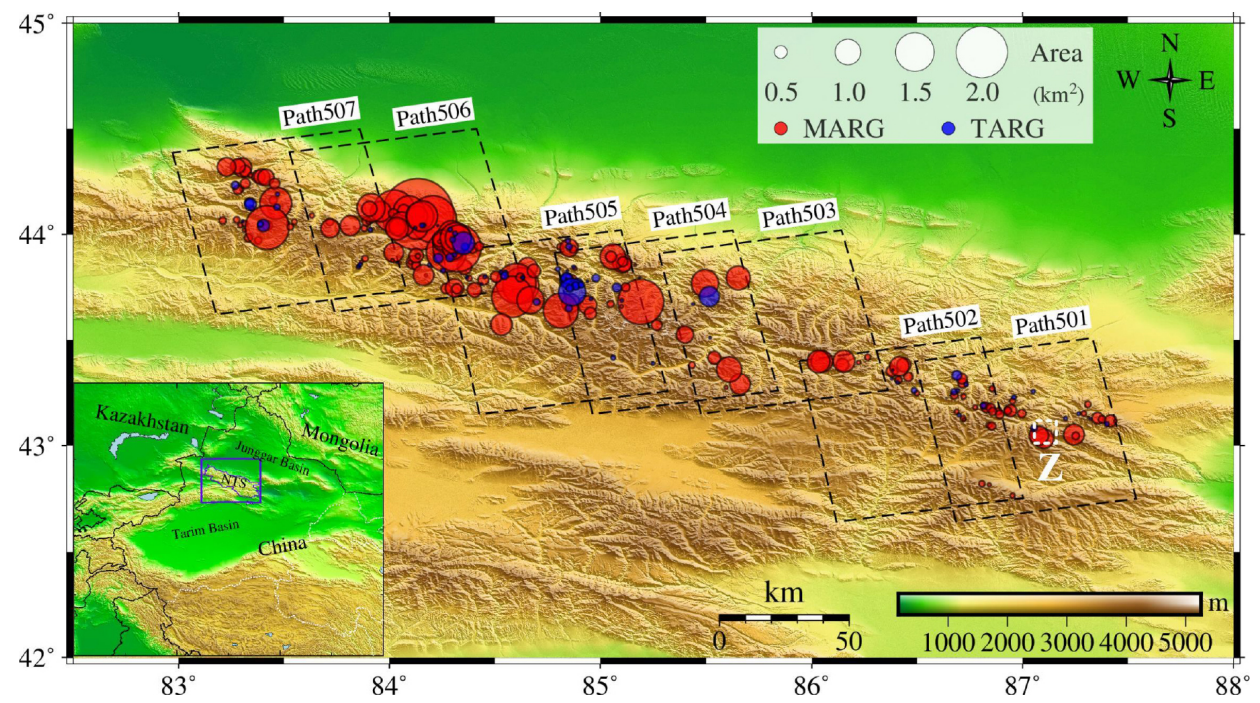

Figure 1. Topography map of the northern Tien Shan (NTS) of China. The black dashed boxes outline the footprints of seven PALSAR frames along paths 501-507. The red and blue circles represent moraine-derived active rock glaciers (MARGs) and talus-derived active rock glaciers (TARGs), respectively. The circle size represents rock glacier area. The white dashed box (labeled as "Z”) is shown in Fig. 3a and b.

Table 1. List of interferograms made from the seven paths of ALOS PALSAR data. Interferogram names are the conjunction of acquisition dates of the two images. The last column gives the number of identified active rock glaciers (ARGs) in each interferogram.

\begin{tabular}{llrrr}
\hline Path/frame & Interferogram & $\begin{array}{r}\text { Time span } \\
\text { (days) }\end{array}$ & $\begin{array}{r}\text { Perpendicular } \\
\text { baseline }(\mathrm{m})\end{array}$ & $\begin{array}{r}\text { Number of } \\
\text { identified ARGs }\end{array}$ \\
\hline $501 / 850$ & $20070902-20071018$ & 46 & 314 & 55 \\
$502 / 850$ & $20070619-20070919$ & 92 & 365 & 20 \\
$503 / 860$ & $20070706-20071006$ & 92 & 340 & 3 \\
$504 / 860$ & $20080424-20080609$ & 46 & -12 & 36 \\
$505 / 860$ & $20080209-20080326$ & 46 & 211 & 57 \\
$506 / 870$ & $20070711-20070826$ & 46 & 256 & 78 \\
$507 / 870$ & $20090802-20090917$ & 46 & 586 & 51 \\
\hline
\end{tabular}

ally smaller than $5 \mathrm{~m}$ (Visser et al., 2014). We selected the images that were cloud free and taken in summer seasons with limited snow cover, which facilitates our visual identification. ARGs are characterized by distinct flow features and structural patterns. Transversal or longitudinal flow features (ridges and furrows) are common on ARGs due to the deformation of internal ice (Clark et al., 1998; Humlum, 2000; Haeberli et al., 2006; Berthling, 2011). Many ARGs also have structural patterns such as the steep frontal slopes and side slopes with swollen bodies. Due to the constant supply of talus or debris, the surface textures of ARGs are usually different from the surrounding slopes, and their surface slopes usually have little or no vegetation. Based on these criteria, we visually examined the landforms in the Google Earth images that correspond to the moving targets in the interferograms and identified the ARGs. We marked the geographical location of each identified ARG and delineated its outline using Google Earth. We distinguished ARGs from debris-covered glaciers based on the decorrela- tion conditions of interferograms and their different visual features on the Google Earth images. Compared with rock glaciers, debris-covered glaciers generally move much faster (Janke et al., 2015), which results in large areas of decorrelation in our PALSAR interferograms. The surface of a debris-covered glacier is usually characterized by ice cliffs and supraglacial lakes (Bolch et al., 2007). The rooting zones of debris-covered glaciers are continuous with clean glacier ice (Davies et al., 2013; Lukas et al., 2007).

Based on the sources of rock materials that input into the surfaces and internal bodies of rock glaciers, we further classified the inventoried ARGs into two categories: morainederived active rock glaciers (MARGs) and talus-derived active rock glaciers (TARGs). MARGs develop beneath the end moraines of glaciers and transports mainly reworked glaciogenic materials (Lilleøren et al., 2013; Scotti et al., 2013). TARGs develop below talus slopes in which there is no visible ice upslope of the landform body and hence transport mainly rock fragments generated from the adjacent rock 

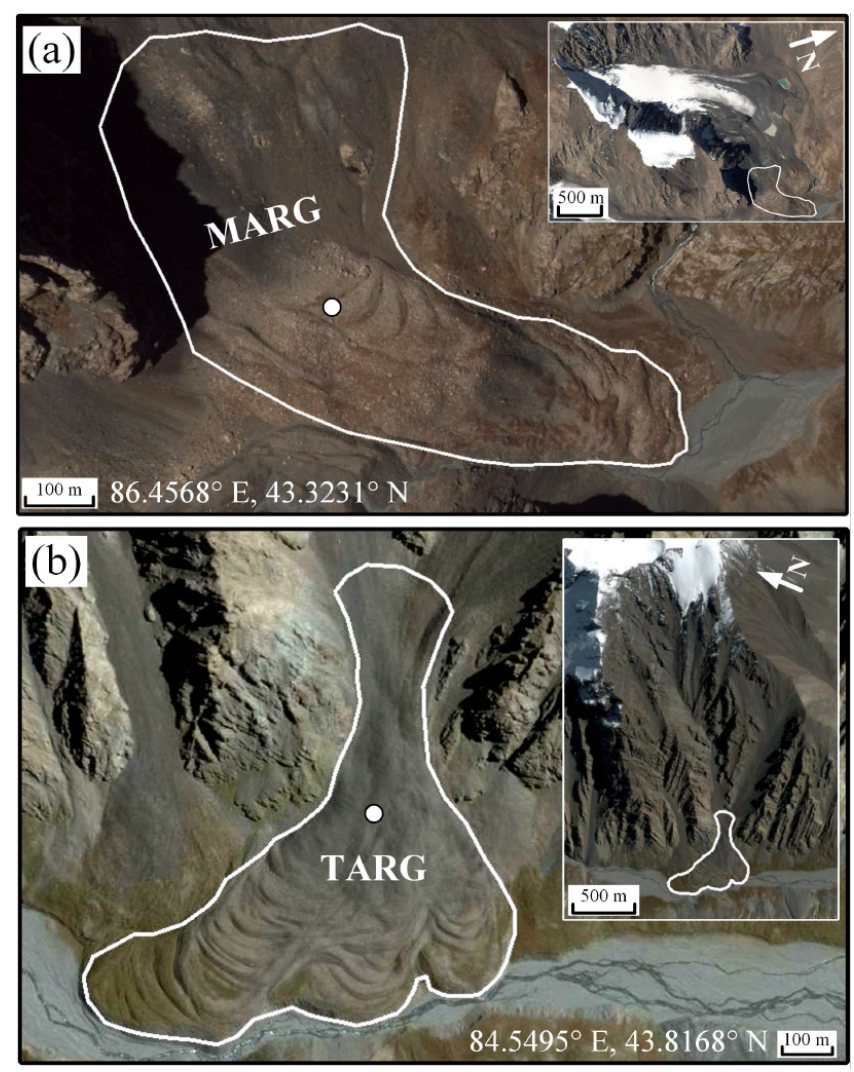

Figure 2. Google Earth images of (a) a typical moraine-derived active rock glacier (MARG) and (b) a talus-derived active rock glacier (TARG). The white dots represent the central location of the ARGs with their longitude and latitude given at the bottom of the figures. The inset images show the topographic and morphologic features surrounding the same rock glaciers.

walls (Lilleøren and Etzelmüller, 2011). For example, Fig. 2a and $b$ show a typical MARG and TARG, respectively. In addition, we found some rock glaciers merge to form a complex, and we classified the sub-branches as different rock glaciers in our inventory based on their different aspect angles.

We demonstrate the method described above using the identified ARGs in the zone "Z" (see its location in Fig. 1), which has an area of about $90 \mathrm{~km}^{2}$. Figure 3a shows the wrapped interferometric phase for this zone. The interferogram was made using images taken 46 days apart in 2007, on 2 September and 18 October, respectively. This interferogram has good coherence with a mean value of 0.82 , which makes it easy to identify the moving targets based on the phase variations. In the zone " $Z$ ", we found 10 moving targets. We then visually checked the surface geomorphic features of each of the moving targets on the Google Earth image (Fig. 3b) and identified 7 of 10 as ARGs. For the other three moving targets, two are artifacts due to phase errors and the other one is an alluvial fan other than rock glaciers; we grouped these three as non-rock glaciers. For a closer inspec- tion, we zoom into the rock glacier in the northwest corner in Fig. 3a. Figure 3c shows that outline determined from the variations of interferometric phases. Figure $3 \mathrm{~d}$ shows the corresponding Google Earth image.

\subsection{Deriving the surface velocity}

We further estimated ground displacements using the InSAR measurements. We unwrapped the interferograms using the minimum cost flow method by selecting a reference point in the flat area with high coherence. For any ARG located in the overlapping regions of two adjacent paths, we selected the interferogram with a higher coherence on the ARG to derive the surface velocity. Previous studies indicated that phase unwrapping is a major limiting factor to the use of SAR interferometry for monitoring active rock glaciers (Barboux et al., 2015). Phase unwrapping may fail in the areas where phase gradients are large due to fast slope movements. To minimize the phase unwrapping errors, we applied the phase filtering with a window of $8 \times 8$ pixels and masked out the decorrelated areas with a coherence threshold of 0.3 before phase unwrapping. We chose a local reference patch $(3 \times 3$ pixels $)$ near but outside each ARG to calibrate the unwrapped phase. We then calculated the surface velocities of the ARGs by dividing the displacements by the temporal span of the interferogram. We then converted the InSAR-estimated velocities in the line-of-sight direction $\left(V_{\mathrm{LOS}}\right)$ into the downslope direction $\left(V_{\text {slp }}\right)$ using the following equation (Liu et al., 2013):

$$
V_{\mathrm{slp}}=\frac{V_{\mathrm{LOS}}}{\sin (\alpha-\beta) \sin \theta_{\mathrm{inc}} \cos \theta_{\mathrm{slp}}+\cos \theta_{\mathrm{inc}} \sin \theta_{\mathrm{slp}}},
$$

where $\alpha$ is the flight direction of the SAR satellite measured from the north; $\theta_{\text {inc }}$ is the local incidence angle, which can be calculated based on the SAR looking geometry and local topography (i.e., digital elevation model) data; $\beta$ and $\theta_{\text {slp }}$ are the aspect angle and slope angle of the ARG, respectively. Finally, we calculated the mean value of all pixels within each ARG to represent its overall velocity.

\subsection{Characterizing the geomorphic and climatic parameters of active rock glaciers}

To characterize the geomorphic features of the ARGs, we first determined the initial line point (ILP) and front line point (FLP) of each ARG, respectively. According to the definition given by Humlum (1998) and Sattler et al. (2016), the ILP is usually located in the rooting zone of a rock glacier and represents the place where permafrost creep starts. Given that the interferometric phase variations represent ground movements, we can outline an ARG by identifying where interferometric phase starts to vary from the local background. We interpreted the boundary in the rooting zone of an ARG as the initial line where the permafrost starts to creep. If InSAR coherence was low in the rooting zone, we used morphologic features such as ridges and furrows instead to determine the 

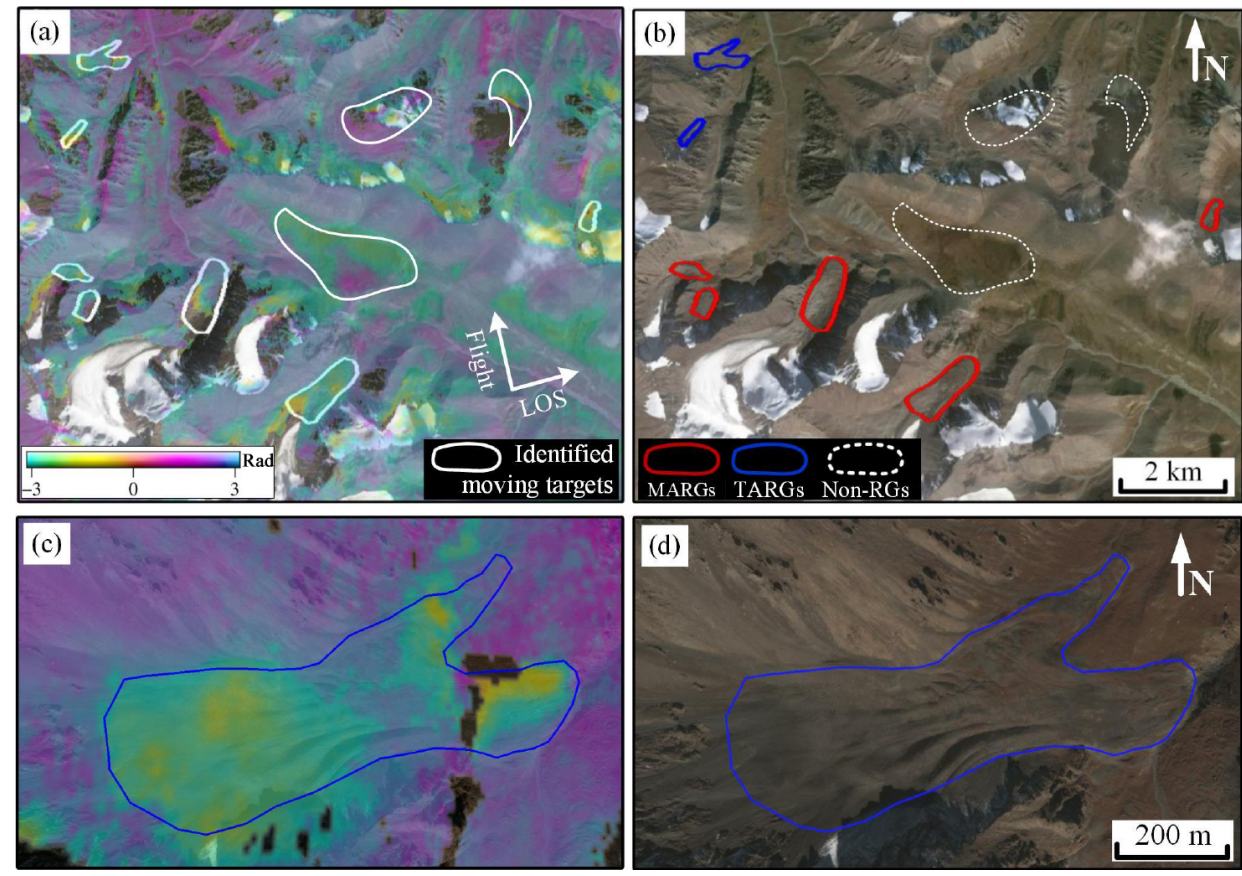

Figure 3. Examples of the identified active rock glaciers in the zones " $Z$ " shown in Fig. 1. (a) shows the wrapped interferometric phase (in radians) for the pair 20070902-20071018 (Path 501). The solid white polygons denote the identified moving targets. (b) shows the corresponding Google Earth image, in which the red and blue polygons denote the identified MARGs and TARGs, respectively. The dashed white polygons denote moving targets that are not rock glaciers (labeled as "Non-RGs"). (c) and (d) show the interferometric phase and optical image for the rock glacier in the northwest corner of (a), respectively.

initial line. We then used the central point of the initial line as the ILP for an ARG. The FLP, the lowest place where a rock glacier can reach, could be easily identified from InSAR and Google Earth images. Figure 4 gives an example showing the determined ILP and FLP for a typical TARG.

We also quantified the geomorphic (including altitude, area, length, shape, slope angle, and aspect angle) and climatic parameters (MAAT and potential income of solar radiation, PISR) of each ARG. We determined the altitudes of the ILP and FLP from the SRTM digital elevation model. We then calculated the slope distance $(L)$, mean slope angle $\left(\theta_{\text {slp }}\right)$, and the mean aspect angle $(\beta)$ based on the coordinates of ILP and FLP. Dividing the area by the square of length gives the aspect ratio, which distinguishes tongueshaped (aspect ratio $<1$ ) from lobate-shaped (aspect ratio $>1)$ ARGs. We extracted the MAAT at the FLP from the NCAR/NCEP global climate reanalysis and interpolated station measurements released by Gruber (2012). We calculated the PISR over 1 year (units: $\mathrm{W} \mathrm{m}^{-2}$ ) using the method described by Kumar et al. (1997) with the assistance of the digital elevation model.

With some assumptions, we performed a simple error analysis about the rock glacier parameters we estimated. First, with the high-resolution interferogram maps and Google Earth images, we estimated that the location of each ARG and FLP/ILP we determined is accurate within $50 \mathrm{~m}$ (i.e., about 3 times the InSAR spatial resolution). The uncertainties of the FLP and ILP altitudes are $16 \mathrm{~m}$, the nominal vertical accuracy of the SRTM digital elevation model. The uncertainties of the other geometric parameters can be estimated by error propagation. For instance, given a rock glacier with a length of $1000 \mathrm{~m}$, an aspect angle of $80^{\circ}$, and a slope angle of $12^{\circ}$, we estimated that the uncertainties for length as $67.2 \mathrm{~m}$, aspect as $3.8^{\circ}$, and slope as $1.6^{\circ}$. We calculated that the mean coherence of each ARG and consequently estimated the uncertainty of the mean InSAR measurements based on the empirical method of Hanssen (2001). We then estimated the uncertainties of surface velocities by using the error propagation law based on Eq. (1). The uncertainties of other geometric parameters (i.e., area and aspect ratio) are difficult to quantify due to the irregular shapes of the ARGs.

Finally, we compiled a spreadsheet to summarize the characteristics of the inventoried ARGs (see the Supplement). Our inventory lists the geographical locations (including longitude, latitude, and altitude), the geomorphic attributes (including area, length, aspect ratio, slope angle, and aspect angle), the climatic factors (i.e., PISR and MAAT), and the surface velocity and its associated uncertainty of each rock glacier. 


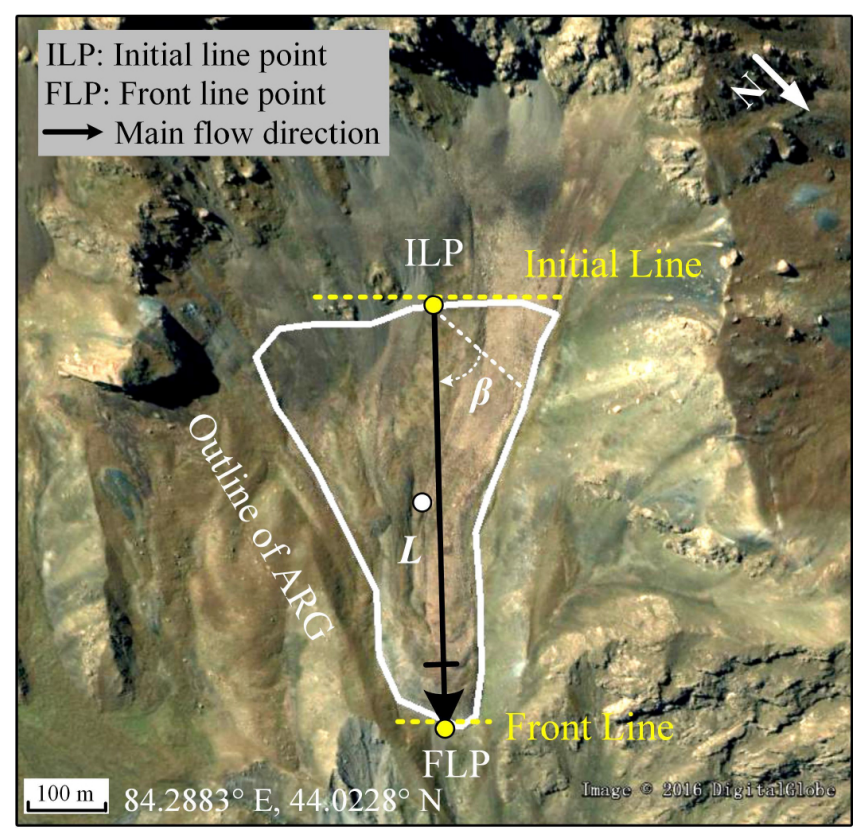

Figure 4. Google Earth image of a typical active rock glacier (ARG), with labels showing its initial line point (ILP), front line point (FLP), length $(L)$, and aspect angle $(\beta)$. The longitude and latitude give the location of the central point (white dot) of the ARG.

\section{Results}

We identified and mapped a total of 261 ARGs across the NTS (see Fig. 1). Table 1 lists the number of ARGs identified in each satellite path. The number of ARGs we compiled is a conservative estimation of all the ARGs in the NTS due to the following three reasons. First, we may have missed some ARGs due to the geometric distortions such as shadows and layovers in the SAR images. For the PALSAR images used in this study, the rock glaciers facing east with the slope angles larger than $51.3^{\circ}$ are in the radar shadows, and the rock glaciers facing west with slope angles larger than $38.7^{\circ}$ are in the layover regions. These distortions would result in significantly phase decorrelation and make it difficult to identify rock glaciers in these regions. Second, ARGs facing nearly north or south might also have been missed, as InSAR (using images from all space missions, including ALOS) is not sensitive to ground motions along these directions. Finally, some small ARGs could not be identified as the interferogram maps have a moderate resolution of about $15 \mathrm{~m}$.

In the following subsections, we first present some general statistics of the inventory (Sect. 4.1). We then characterize the altitude distribution of the ARGs in Sect. 4.2 and describe the surface velocities of the ARGs in Sect. 4.3.

\subsection{General statistics of the inventory}

Table 2 provides the overall information of the inventoried ARGs in the NTS. Among the 261 ARGs we mapped, 179
(69\%) are MARGs and $82(31 \%)$ are TARGs. The MARGs are generally longer, steeper, and larger than the TARGs. The mean FLP altitudes for three groups - namely, all the ARGs, the MARGs, and the TARGs - are 3174, 3208, and $3099 \mathrm{~m}$, respectively. Their mean ILP altitudes are 3486,3516 , and $3420 \mathrm{~m}$, respectively. These figures indicate that the favorable altitude for ARGs in the NTS is above $3000 \mathrm{~m}$, which is consistent with the previous reports of Liu et al. (1995) and Zhu et al. (1992). Most of the ARGs are tongue-shaped, with a mean aspect ratio of about 0.25 . The mean area of the MARGs is nearly twice as large as that of the TARGs. The ARGs cover a total area of about $91.5 \mathrm{~km}^{2}, 85 \%$ of which is occupied by MARGs.

Taking all ARGs as a single group, their ILP altitudes and FLP altitudes both show nearly norm distribution (Fig. 5a and d). The majority of ARGs have the ILP altitudes higher than about $3300 \mathrm{~m}$ (Fig. 5a) and the FLP altitudes higher than about $3000 \mathrm{~m}$ (Fig. 5d). ILP and FLP altitudes show different statistic distributions between the MARGs and TARGs. The histogram of ILP altitude for the MARGs shows a sharp increase at about $3300 \mathrm{~m}$ and a sharp decrease at about $3800 \mathrm{~m}$ (Fig. 5b). In contrast, the histogram of ILP altitude for the TARGs shows a nearly even distribution, though with some degree of randomness (Fig. 5c). The FLP altitudes for MARGs and TARGs both show nearly norm distributions (Fig. 5e-f). The minimum, median, and maximum FLP altitudes of the MARGs are all higher than those of the TARGs, indicating that the MARGs develop on higher slopes than the TARGs.

In the inventory, 182 (or $70 \%$ ) of the ARGs are located on north-facing (defined between NW and NE) slopes (Fig. 6a), with the NE aspect predominating (56\%), indicating the north-facing slopes are the most suitable slopes for rock glacier development and formation in the NTS. The number of north-facing MARGs and TARGs are 134 and 48 accounting for the 75 and $59 \%$ of the total numbers of MARGs and TARGs, respectively. The difference is probably because the aspect distribution of the glaciers, which influence the aspect of MARGs as the evolution of MARGs are controlled by the input glacier moraines. We also noted that the majority of glaciers in the NTS are north-facing, controlled by topography, climate, and geometric factors (Aizen et al., 1995; $\mathrm{Li}$ and $\mathrm{Li}, 2014)$. Compared with the MARGs, the TARGs are more evenly distributed across all aspects. This pattern is consistent with that found in rock glaciers in the central Italian Alps and Southern Carpathians (Scotti et al., 2013; Onaca et al., 2016).

The subsurface thermal condition is another major factor controlling the development of ARGs, which is influenced by solar radiation. Figure $6 \mathrm{~b}$ shows the variations of PISR with the aspect angles. The mean value of PISR for the northfacing and south-facing slopes are $8.83 \times 10^{5} \mathrm{~W} \mathrm{~m}^{-2}$ and $10.46 \times 10^{5} \mathrm{~W} \mathrm{~m}^{-2}$, respectively. The south-facing ARGs typically receive higher PISR than their north-facing counterparts. As most of the ARGs are north-facing, we conclude 
Table 2. Statistical summary of the inventoried active rock glaciers. Each column gives the mean values and the standard deviations (the values in brackets) of the parameters.

\begin{tabular}{lrrrrrrrr}
\hline & Number & $\begin{array}{r}\text { FLP altitude } \\
(\mathrm{m})\end{array}$ & $\begin{array}{r}\text { ILP altitude } \\
(\mathrm{m})\end{array}$ & $\begin{array}{r}\text { Length } \\
(\mathrm{m})\end{array}$ & $\begin{array}{r}\text { Aspect ratio } \\
(-)\end{array}$ & $\begin{array}{r}\text { Slope } \\
\left({ }^{\circ}\right)\end{array}$ & $\begin{array}{r}\text { Area } \\
\left(\mathrm{km}^{2}\right)\end{array}$ & $\begin{array}{r}\text { Total area } \\
\left(\mathrm{km}^{2}\right)\end{array}$ \\
\hline All ARGs & 261 & $3174(262)$ & $3486(208)$ & $1341(899)$ & $0.25(0.19)$ & $14(6)$ & $0.35(0.33)$ & 91.5 \\
MARGs & 179 & $3208(264)$ & $3516(180)$ & $1521(988)$ & $0.24(0.14)$ & $11(4)$ & $0.43(0.36)$ & 77.4 \\
TARGs & 82 & $3099(243)$ & $3420(247)$ & $947(465)$ & $0.25(0.18)$ & $19(4)$ & $0.17(0.14)$ & 14.1 \\
\hline
\end{tabular}
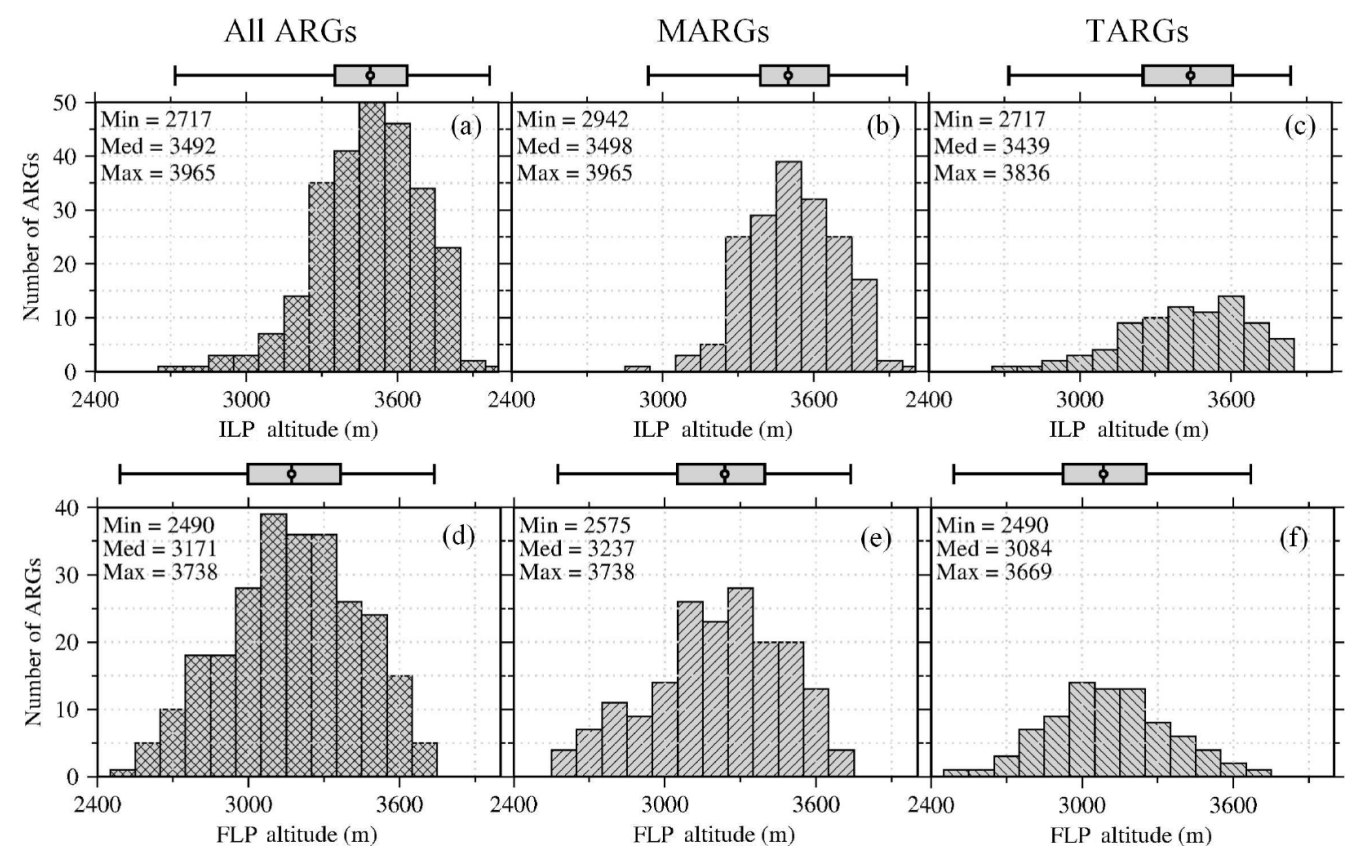

Figure 5. Histograms of the ILP altitudes (a-c) and FLP altitudes (d-f) for all ARGs, MARGs, and TARGs, respectively. The minimum (Min), median (Med), and maximum (Max) values for the ILP altitudes and FLP altitudes are denoted. Their units are meters. The box on the top of each subfigure denotes the box-and-whisker symbol, which gives the locations of the minimum, the $25 \%$ quantile, the $50 \%$ quantile, the $75 \%$ quantile, and the maximum values. The altitudes are derived from the SRTM digital elevation model data.

that slopes with lower PISR favor the presence of ARGs. This is probably because lower PISR helps to preserve ground ice inside ARGs.

\subsection{Altitudinal distribution of the active rock glaciers}

To explore how the factors would impact the altitude distribution of the ARGs, we calculated the Pearson correlation coefficients between the FLP altitudes and the environmental factors listed in Sect. 3.3. FLP altitude denotes the lowest altitude that an ARG can reach and is frequently used as the lower boundary for the presence of mountain permafrost locally (Lilleøren et al., 2013; Schmid et al., 2015). For the ARGs in our inventory, the correlation coefficients between the FLP altitudes and the longitude, latitude, MAAT, PISR, slope angle, and aspect angle are $0.47,-0.51,-0.86,0.29$, -0.35 , and -0.08 , respectively.

The simple correlation analysis confirms the strong influence of the geographical locations on the altitude distribution of the ARGs (Fig. 7a and b). The FLP altitudes generally increase from west to east and decrease from south to north. This spatial pattern could be mainly because the NTS lays with a strike of about $\mathrm{N} 20^{\circ} \mathrm{W}$ extending from northwest to southeast. Along this direction, the air temperature increases with lower latitude, thus increasing the lowest altitude for the development of rock glaciers. Moreover, glaciers would also influence the altitude distribution of ARGs as MARGs generally develop beneath the end moraines of glaciers. The western part of the NTS is relatively more humid. Thus, the larger and longer glaciers would develop and cause the MARGs in the west to have lower FLP altitudes than the eastern ones.

Additionally, we found different altitude distributions of ARGs in the western and eastern parts (Fig. 7a). The nearly linear pattern in the east is more apparent than that in the west. We performed a $t$ test on the similarity of the FLP altitude distributions in the two subregions. The $p$ value is smaller than 0.01 at the $95 \%$ confidence level. Therefore, we 


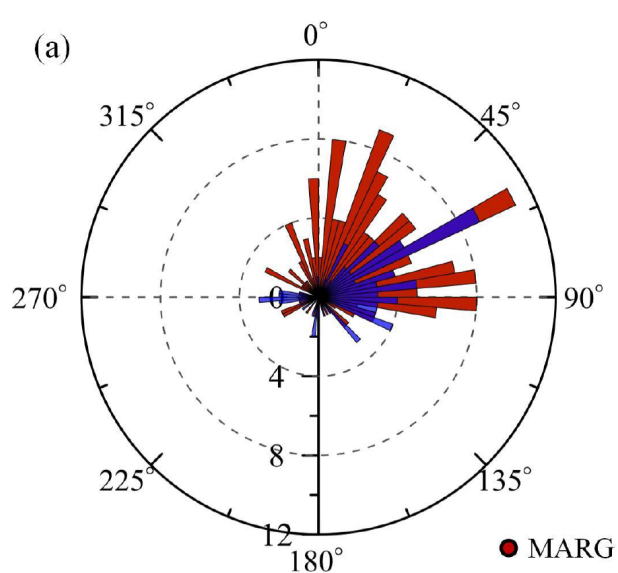

Number of ARGs

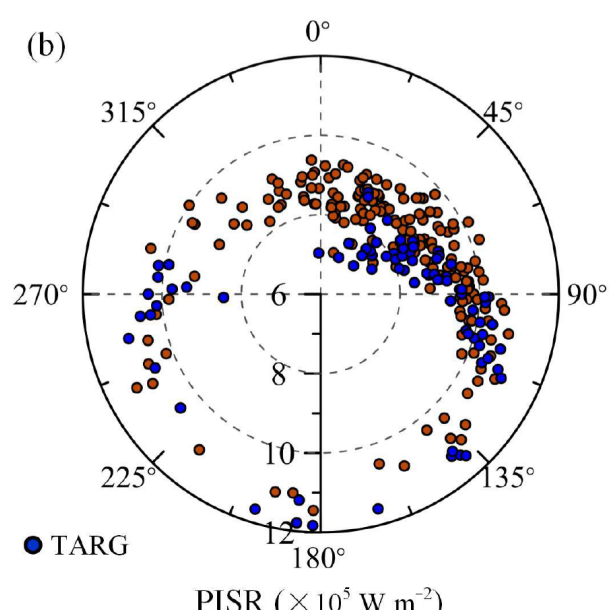

$\operatorname{PISR}\left(\times 10^{5} \mathrm{~W} \mathrm{~m}^{-2}\right)$

Figure 6. (a) Histogram of the aspect angles for the MARGs (red) and TARGs (blue), respectively. (b) Wind rose plot shows the variations of potential income of solar radiation (PISR) with aspect angles.

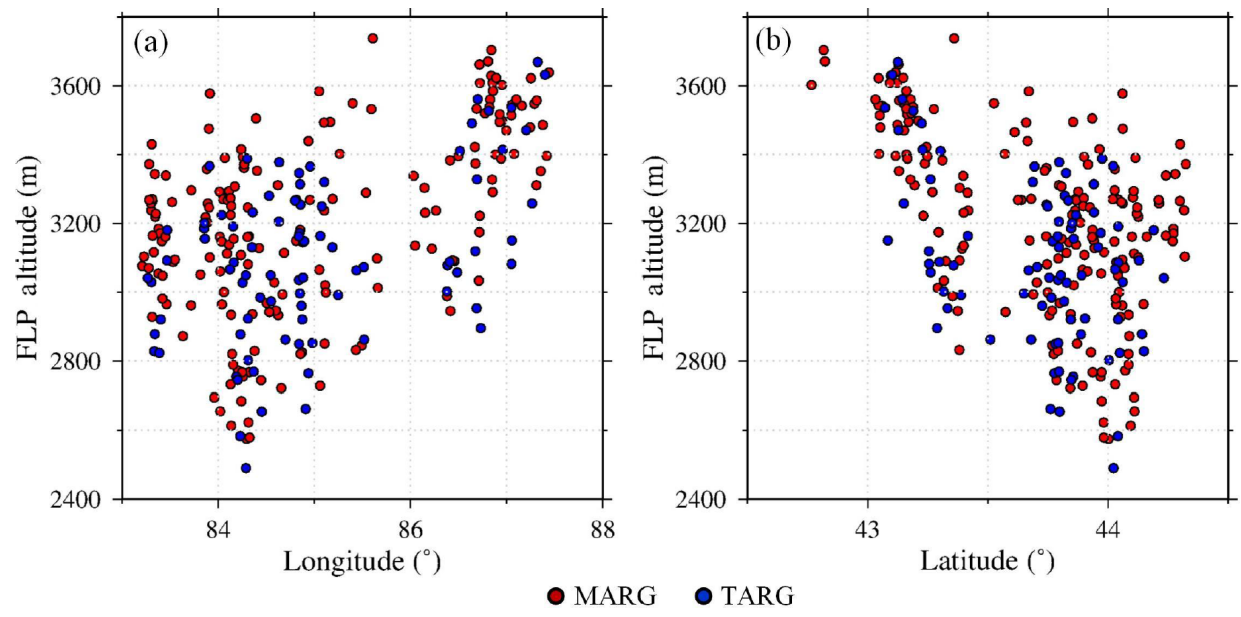

Figure 7. Scatter plots between the FLP altitudes and (a) the longitude and (b) latitude.

conclude that the altitude distribution in the western NTS is significantly different from those located in the eastern part. The relatively scattering pattern in the west indicates that the altitude distributions of the ARGs there are not dominantly controlled by the geographical location (i.e., longitudes). There could be other factors influencing the altitude distributions in the west. For instance, Bolch and Gorbunov (2014) revealed that the characteristics of the contributing area (e.g., the area, slope, and elevation range) of rock glaciers would influences their altitude distribution as well.

The correlation analysis also reveals the relative importance of various factors to the rock glacier distributions. The highest correlation coefficient is found at the factor "MAAT". Although the blocky material of the rock glaciers may lower the ground temperature from the air temperature, this high correction implies that the MAAT may influence ground thermal conditions and thus the formation, evolution, and sur- vival of the ARGs. A moderate positive correlation is observed at the factor "PISR". Receiving a higher PISR, the ground temperature is likely higher and the internal ice is more likely to melt. The correlation between the slope angles and FLP altitudes is associated with the favorable presence of TARGs on the steep slopes. We found no obvious correlation between the aspect angles and FLP altitudes.

\subsection{Surface velocities of the active rock glaciers}

We were conservative in conducting statistical analyses on the surface velocities by only including the ARGs with a mean coherence higher than 0.3 and a mean velocity larger than $5 \mathrm{~cm} \mathrm{yr}^{-1}$. Finally, the surface velocities of 170 ARGs (including 111 MARGs and 59 TARGs) were documented (Fig. 8). The surface velocities of the 170 ARGs show a spatially heterogeneous pattern over the NTS. Most of ARGs $(84 \%)$ have surface velocities lower than $60 \mathrm{~cm} \mathrm{yr}^{-1}$. The 


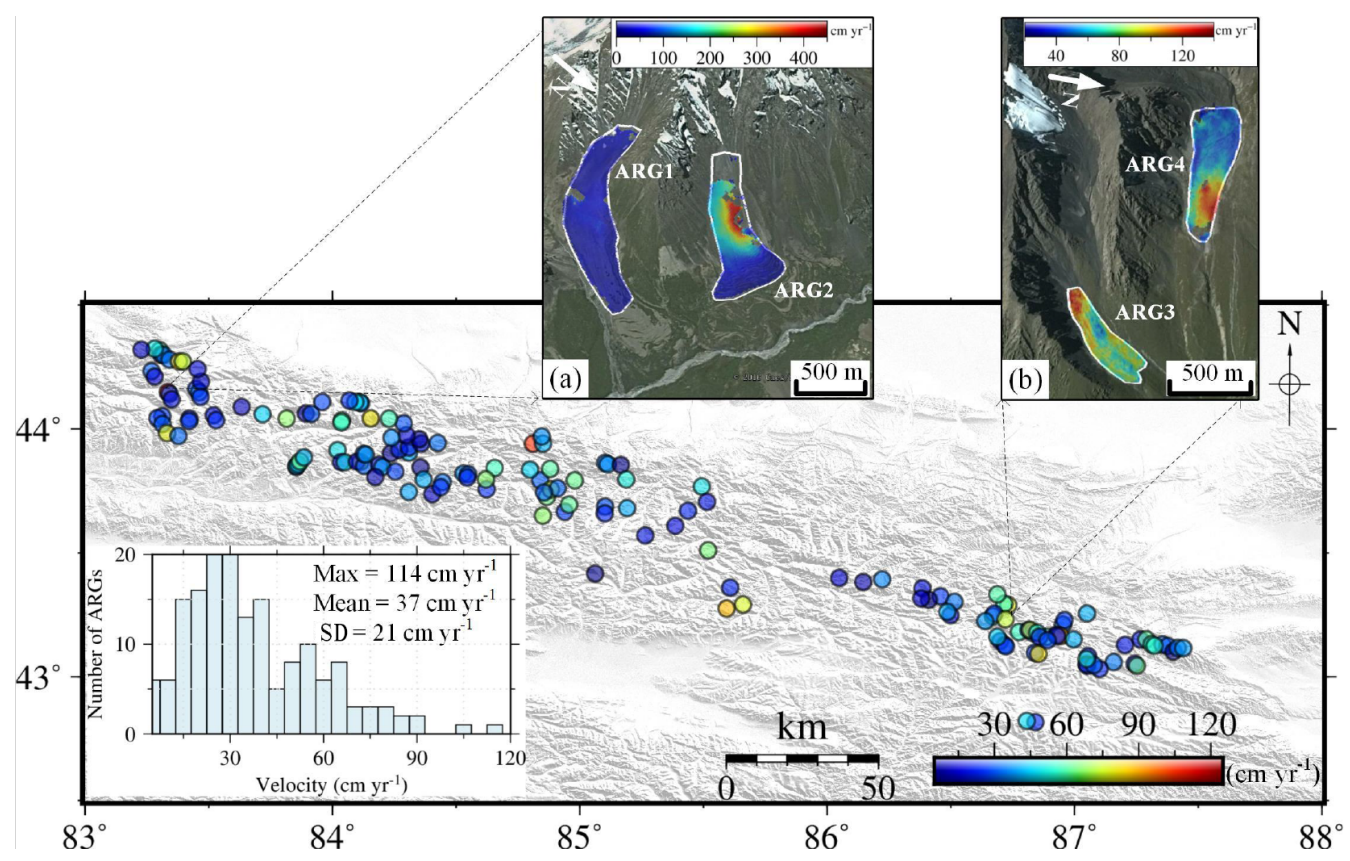

Figure 8. The bottom map shows the downslope velocities of 170 ARGs measured from SAR interferometry, with the histogram shown in the inset. The top two figures show the downslope velocities of two pairs of ARGs adjacent to each other. Note that different velocity color bars are used.

maximum surface velocities in the eastern and western parts are about 89 and $114 \mathrm{~cm} \mathrm{yr}^{-1}$, respectively. The mean velocity and the standard deviation of all ARGs are $37 \mathrm{~cm} \mathrm{yr}^{-1}$ and $21 \mathrm{~cm} \mathrm{yr}^{-1}$, respectively. The maximum velocity uncertainty is $29 \mathrm{~cm} \mathrm{yr}^{-1}$, and the mean uncertainty is $8 \mathrm{~cm} \mathrm{yr}^{-1}$.

We selected two pairs of ARGs to inspect the spatial variations of surface velocities closely (Fig. 8a-b). The two ARGs in each pair are adjacent to each other. Therefore, we assumed that they developed in similar topo-climatic environments (e.g., similar altitude, MAAT, and precipitation). The surface velocities of "ARG1" show a spatial homogeneity pattern while these of the other three all show a spatially heterogeneous pattern. The fastest moving zones are located near the center, the rooting zone, and the front of "ARG2", "ARG3", and "ARG4", respectively. This significant heterogeneity of surface velocities within ARGs indicates that the kinematics of surface movements are complex. Previous studies have demonstrated that the surface velocities ARGs are not only influenced by topo-climatic factors but also the ice condition and internal structure of ARGs (Haeberli et al., 2006; Serrano et al., 2010; Schoeneich et al., 2015). However, it is difficult to determine and quantify the ground ice conditions or ground thermal conditions of the ARGs in this study. Nevertheless, the spatial variabilities of velocities at both the local and regional scales suggest that the dynamics of ARGs are not controlled by any single factor, but a combination of many factors.

In addition, the SAR images we used were acquired at different times, which may also contribute to the spatial hetero- geneity of the surface velocities. We used seven pairs of PALSAR images, one from each path, to cover the study area. However, the acquisition times for each image pairs are different (Table 1). Recent studies show that the surface velocity of rock glacier may vary seasonally (Liu et al., 2013; Wirz et al., 2016). Moreover, strong precipitations or snowmelt may also influence the surface velocities. In this study, we simply chose these PALSAR images for the inventory exercise and ignored the temporal dynamics of rock glaciers.

\subsection{Lower limit of permafrost occurrence in the northern Tien Shan}

We used the inventoried ARGs as a proxy of permafrost to infer lower limit of permafrost occurrence in the NTS. The previous estimates of the lower limit of permafrost presence in the NTS were mainly based on field surveys near the Ürümqi River source region $\left(87.00^{\circ} \mathrm{E}, 43.07^{\circ} \mathrm{N}\right)$ in the east and near the Haxilegen Pass region $\left(84.45^{\circ} \mathrm{E}, 43.77^{\circ} \mathrm{N}\right)$ in the west (Qiu et al., 1983; Jin et al., 1993; Qiu, 1993). However, these site-based estimations may not be representative of the whole study area. Therefore, the ARGs we inventoried are valuable for re-estimating the permafrost distribution for this region. Permafrost is unlikely to develop below the FLP, and the proportion and extent of permafrost usually increase towards higher altitudes. Because our inventory shows that MARGs generally develop on higher slopes than TARGs (see Sect. 4.1), here we only used the FLP altitudes of TARGs to estimate the lower limit of permafrost. 


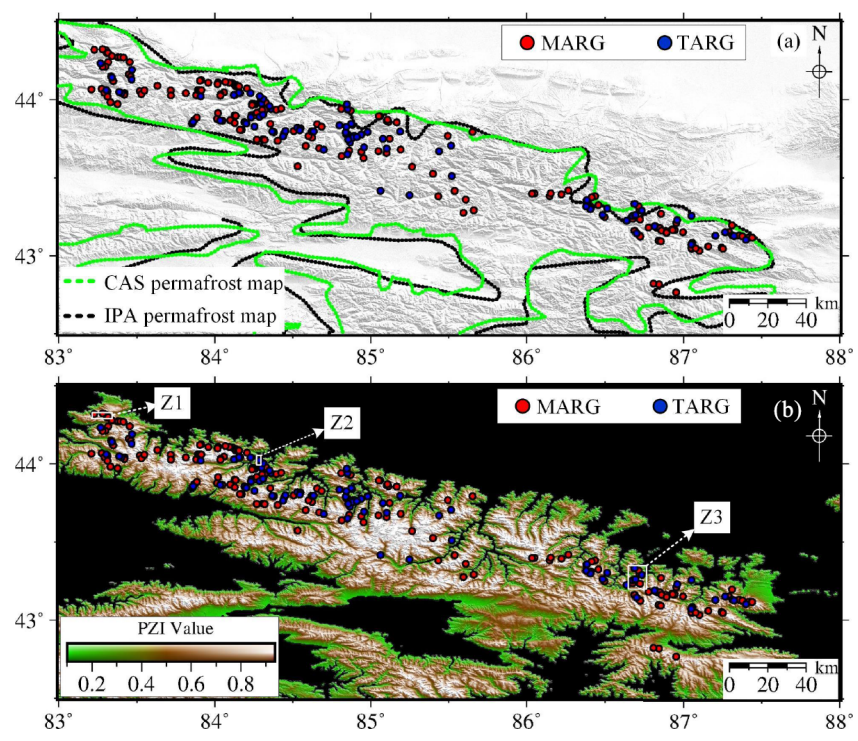

Figure 9. Comparison between the mapped ARGs and existing permafrost maps. The green and black dashed lines in (a) show the mountain permafrost boundaries of CAS permafrost map and the discontinuous permafrost boundaries of IPA map, respectively. The green-to-white colors in (b) show the global Permafrost Zonation Index (PZI) values. Areas without PZI values are shown in black. The PZI maps for the three selected zones "Z1", "Z2", and "Z3" in (b) are further shown in Fig. 10. The red and blue dots mark the locations of MARGs and TARGs, respectively.

We grouped the inventoried TARGs into different categories based on their locations (i.e., east and west of $86^{\circ} \mathrm{E}$ ) and aspect angles (i.e., north-facing and south-facing) to infer the lower limit of permafrost under different environmental conditions. The first row of Table 3 summarizes their altitudinal limits: 2490 and $2583 \mathrm{~m}$ for the north-facing and south-facing slopes in the west, respectively, and 2895 and $3088 \mathrm{~m}$ for the north-facing and south-facing slopes in the east, respectively. Overall, the altitudes of the inventoried ARGs increase from west to east as shown in Fig. 7a.

However, these estimates may not give an entirely accurate picture of the permafrost limit for the whole study area, because they are based on a few specific ARGs that have the lowest FLP altitudes in the inventory. For example, the TARG with the lowest FLP altitude (i.e., $2490 \mathrm{~m}$ ) is located on a north-facing slope in the western part of the NTS (shown in Fig. 10b, outlined by the blue polygon). We cannot rule out the possibility that this particular ARG may be a local anomaly and therefore cannot fully represent the permafrost presence in the broader NTS. Thus, we adopted an alternative method in a statistical sense, which approximates the lower limit of permafrost by subtracting the standard deviation of all FLP altitudes in the inventory from their mean values. The second row of Table 3 lists these statistics-based estimates: 2772 and $2828 \mathrm{~m}$ for the north-facing and south-facing slopes in the west, respectively, and 3005 and $3041 \mathrm{~m}$ for the north- facing and south-facing slopes in the east, respectively. The largest difference between the statistics-based and lowestaltitude-based estimates is $282 \mathrm{~m}$, indicating that both estimates are consistent, although the statistics-based values are normally higher. Therefore, we suggest the lower limit for the permafrost distribution in the NTS is about $2500-2800 \mathrm{~m}$.

The third row of Table 3 summarizes the field-based estimates of the lowest altitude of permafrost given by Qiu et al. (1983). We note that the results of the field surveys are all higher than these inferred from our lowest-altitude-based estimates. We also note that the field-based results are all lower (and higher) than our statistics-based estimates for the northfacing (and south-facing) slopes. The largest differences between the lowest-altitude-based and the field-based estimates are 467 and $162 \mathrm{~m}$ for the western and eastern parts, respectively. The largest discrepancies between the statistics-based and field-based estimates are 222 and $209 \mathrm{~m}$, respectively. One possible reason for these discrepancies is that our results based on ARG inventory give regional estimates, while the field surveys give site-specific estimates. Additionally, the ARGs move downslope and the fronts of those low-lying ARGs may reach places free of permafrost. Furthermore, the permafrost conditions in the NTS may have changed in the past 2 decades. A recent study shows strong permafrost degradation in the Ürümqi River source region since 1992 (Zhao et al., 2010).

\section{Discussion}

\subsection{Comparisons with the previous studies of rock glaciers in the Tien Shan}

Previous studies of rock glaciers in the NTS are limited with most of them concentrating in the Ürümqi River source region. Interpreting aerial photos acquired in the late 1980s and early 1990s, several researchers (Cui and Zhu, 1989; Zhu, 1992; Zhu et al., 1992; Liu et al., 1995) identified hundreds of rock glaciers in the NTS. They found that most of the identified rock glaciers are tongue-shaped, located at altitudes between 3300 and $3900 \mathrm{~m}$, and facing north. These findings are generally consistent with our inventory. These previous studies also revealed a homogeneity pattern of the ARG surface velocities. Cui and Zhu (1989) and Zhu (1992) measured the movements of the marked boulders on the front slopes of five rock glaciers near the Ürümqi River source region and estimated that their surface velocities varied from 1 to $75 \mathrm{~cm} \mathrm{yr}^{-1}$. Moreover, they found that one rock glacier (referred to as "RG4" in their study) moved at about $49 \mathrm{~cm} \mathrm{yr}^{-1}$ between 1985 and 1986. However, they estimated that its mean velocity was about $6 \mathrm{~cm} \mathrm{yr}^{-1}$ from 1960 to 1986 . Our measurements show that the largest velocity is located the western part of the NTS, which is also consistent with the findings of Cui and Zhu (1989) and Zhu et al. (1992). However, these previous studies did not provide any detailed in- 
Table 3. The lower altitudinal limits of permafrost distribution in the NTS inferred from this study using the inventoried TARGs. "This study (Min)" denotes the altitudinal limits inferred from specific TARGs with the lowest FLP altitudes. "This study (Stat)" denotes the altitudinal limits inferred from the statistics-based calculations of FLP altitudes. The limits from "Field surveys" are based on the work of Qiu et al. (1983). The rows "Difference (Min)" and "Difference (Stat)" list the differences between the results inferred from this study and the field surveys, respectively. All the altitudes given by this study are derived from the SRTM digital elevation model data with an uncertainty of about $16 \mathrm{~m}$.

\begin{tabular}{lrrrrr}
\hline & \multicolumn{2}{c}{ West of $86^{\circ} \mathrm{E}$} & & \multicolumn{2}{c}{ East of $86^{\circ} \mathrm{E}$} \\
\cline { 2 - 3 } \cline { 5 - 6 } & North-facing & South-facing & & North-facing & South-facing \\
\hline This study (Min) & $2490 \mathrm{~m}$ & $2583 \mathrm{~m}$ & & $2895 \mathrm{~m}$ & $3088 \mathrm{~m}$ \\
This study (Stat) & $2772 \mathrm{~m}$ & $2828 \mathrm{~m}$ & & $3005 \mathrm{~m}$ & $3041 \mathrm{~m}$ \\
Field surveys & $2730 \mathrm{~m}$ & $3050 \mathrm{~m}$ & & $2900 \mathrm{~m}$ & $3250 \mathrm{~m}$ \\
Difference (Min) & $-240 \mathrm{~m}$ & $-467 \mathrm{~m}$ & & $-5 \mathrm{~m}$ & $-162 \mathrm{~m}$ \\
Difference (Stat) & $42 \mathrm{~m}$ & $-222 \mathrm{~m}$ & & $105 \mathrm{~m}$ & $-209 \mathrm{~m}$ \\
\hline
\end{tabular}

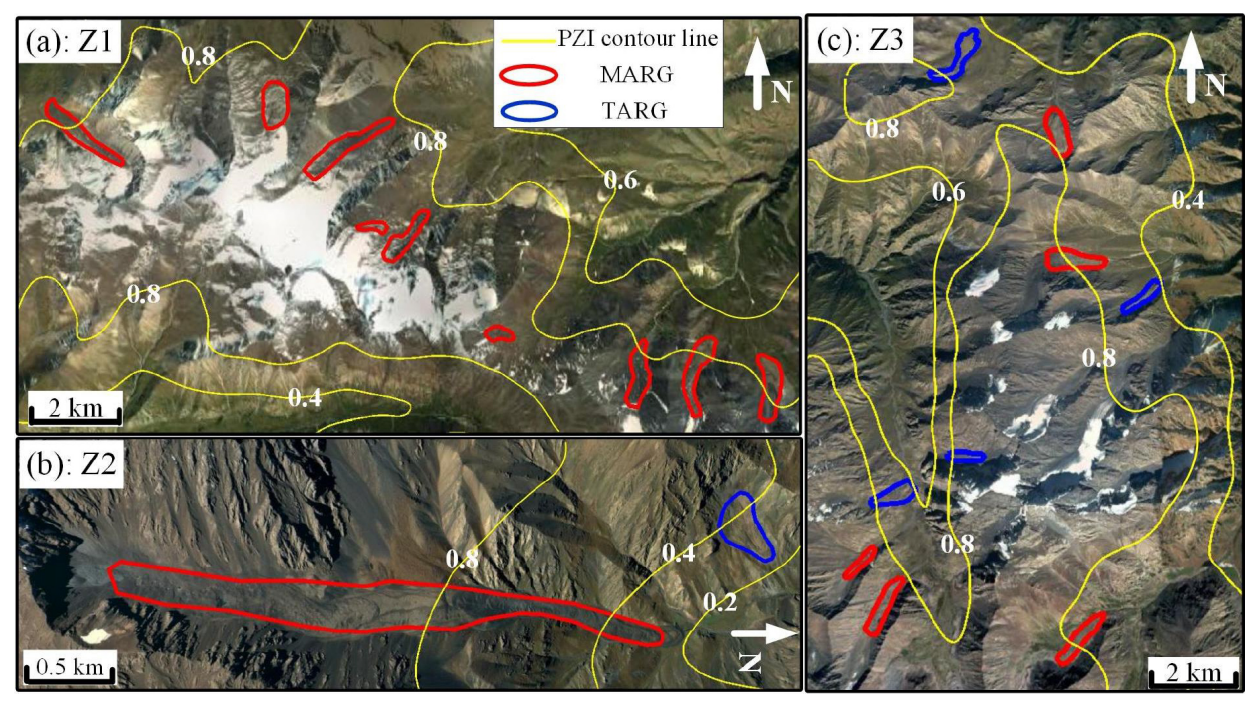

Figure 10. Local PZI maps for the three selected regions "Z1", "Z2", and "Z3" marked in Fig. 9b. (a) and (c) are selected randomly. (b) shows the MARG and TARG with the lowest FLP altitude within the entire study area. The thin yellow lines in (b-d) are contour lines of PZI values. The red and blue polygons outline the MARGs and TARGs, respectively.

formation such as geographical and geomorphic attributes of the identified rock glaciers. Thus, we cannot compare these field-based estimates with our measurements in further detail.

Recent studies of rock glaciers in the Tien Shan have been focusing in two subregions: (1) the Dzungar Alatau in Kazakhstan at about $400 \mathrm{~km}$ northwest of our study area and (2) the Ile-Alatau and Kungöj Ala-Too mountain ranges ( 42.5 to $43.5^{\circ} \mathrm{N}, 75$ to $79^{\circ} \mathrm{E}$ ) at the border between Kazakhstan and Kyrgyzstan. Gorbunov and Titkov (1992) identified about 850 ARGs in the first region. Comparing their inventory with ours, we find that the rock glaciers in Dzungar Alatau are at lower altitudes than that in the NTS, which likely results from their more northerly latitude. Gorbunov et al. (1998) inventoried 1034 rock glaciers in the second region, of which at least 851 are identified to be active. Similar to our results, they found that the MARGs occupy a larger area than the TARGs. We also find the altitudinal distributions of the rock glaciers there are similar to that in the NTS. Studies revealed that the annual displacement rates of the ARGs in these regions range from less than $1 \mathrm{~m} \mathrm{yr}^{-1}$ to about $11 \mathrm{~m} \mathrm{yr}^{-1}$ (Gorbunov and Titkov, 1992; Bolch and Gorbunov, 2014), faster than the ones we mapped in the NTS.

\subsection{Limitations of using active rock glaciers to determine the lower limit of permafrost}

The moderate discrepancies between our estimates and the field surveys of the altitudinal limits for permafrost occurrence in the NTS demonstrated the feasibility of our method to infer the permafrost distribution. However, several factors still exist and limit the accuracy of our method for quantifying the lower limit of permafrost. These factors include (1) the ambiguity about the genesis of rock glaciers, (2) the 


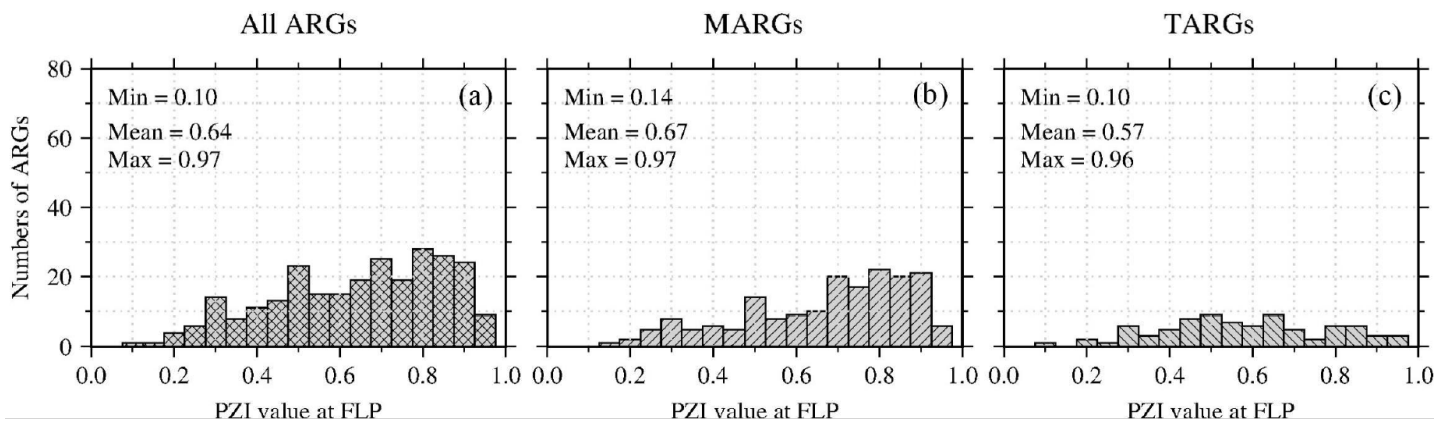

Figure 11. The histograms of the PZI values at the front line point (FLP) for all ARGs (a), MARGs (b), and TARGs (c), respectively.

high heterogeneity of ground thermal regime, and (3) the uncertainties in the use of FLP altitudes of the ARGs to infer permafrost limit.

First, it is still debatable to use active rock glaciers as representatives of the exact permafrost boundaries. There are two contradictory viewpoints regarding the genesis of rock glaciers. One holds rock glaciers are permafrost creep features and form in a permafrost environment. The other one holds that rock glaciers form through a continuum of glacial to periglacial processes and thus they may also be related to glaciers in non-permafrost environments (Clark et al., 1998; Berthling, 2011). To avoid this ambiguity, we only used the talus-derived ARGs in this study to infer the lower limit of permafrost in the NTS.

Second, as shown in Sect. 4.2, the altitudinal distributions of the ARGs in the NTS indicate that the presence of rock glaciers is primarily governed by the ground thermal regime. However, the ground thermal regime in the alpine region can be highly heterogeneous in space. In Trans-Ili Alatau Tien Shan, the mean annual temperatures inside the coarse debris could be $2.5-4.0^{\circ} \mathrm{C}$ cooler than the MAATs because the blocky debris favors cooler temperatures, allowing rock glaciers to exist at elevations where permafrost is otherwise unlikely (Gorbunov et al., 2004). Thus, individual rock glacier only serves as a local indicator of permafrost occurrence. This is why we estimated the lower limit of permafrost occurrence in the regional scale in lowestaltitude-based and statistics-based perspectives. Nevertheless, the statistics show that the mean MAAT at the TARGs is $-5.4^{\circ} \mathrm{C}$, and $83 \%$ of the TARGs have the MAAT lower than $-4{ }^{\circ} \mathrm{C}$. This indicates that the TARGs we used for estimating the lower limit of permafrost are located in a cold environment, and thus reinforcing the credibility of our estimates.

Lastly, several sources of uncertainty exist in the use of FLP altitudes of ARGs to infer the lowest altitude of permafrost occurrence in the NTS. On the one hand, ARGs move downslope and may export permafrost into lower altitudes that are climatically unfavorable for permafrost formation. Thus, our estimates may give a bias towards a lower than the true permafrost limit. On the other hand, we did not identify inactive rock glaciers, which are also indicators of permafrost occurrence. Since inactive rock glaciers generally develop at lower altitudes than active ones (Sollid and Sørbel, 1992), our estimates may bias the permafrost limit towards a higher value. Additionally, we cannot rule the possibility that some extremely low-lying ARGs are not included, which may lower our estimated altitude limits. These three kinds of uncertainties justify the expression of a range of estimations rather than exact values of the altitude limits as given in Sect. 4.4.

\subsection{Comparison with the existing permafrost distribution maps}

We cross-validated the inferred permafrost distribution by comparing our inventoried ARGs with the existing permafrost distribution maps. We selected three permafrost maps that covers the NTS region: (1) the Map of Snow, Ice and Frozen Ground in China released by Cold and Arid Regions Environmental and Engineering Research Institute, Chinese Academy of Sciences (Shi and Mi, 1988), which we refer to as the CAS map; (2) the Circum-Arctic Map of Permafrost and Ground Ice Conditions released by the International Permafrost Association (Brown et al., 1998), referred to as the IPA map; and (3) the global Permafrost Zonation Index (PZI) map developed by Gruber (2012). The frozen ground in the CAS map is classified into highlatitude, plateau, and mountain permafrost with a scale of $1: 4000000$. The IPA map adopts the classes of continuous, discontinuous, sporadic, and isolated patches of permafrost extent with a scale of $1: 1000000$. The PZI map is generated based on the relationships between permafrost extent and long-term MAAT data with a ground resolution of $1 \mathrm{~km}$. The PZI values range from 0 to 1 . Values close to 1 represent permafrost existing in nearly all conditions, while values close to 0 represent permafrost presenting only in the most favorable conditions. The PZI uncertainty is expressed with "fringe of uncertainty", referring to a conservative or an anticonservative variant of the "normal" scenario that considers the possibility of $<10 \%$ permafrost area as well (Gruber, 2012). 
Figure 9 compares the ARGs we inventoried in the NTS with the three permafrost maps described above. The dotted green and black lines in Fig. 9a outline the mountain permafrost extent from the CAS map and the discontinuous permafrost from the IPA map, respectively. The background color map in Fig. 9b shows the PZI values. Most ARGs are located within the permafrost extents of the CAS and IPA maps (256 out of 261 are within the CAS; 249 are within the IPA). We also found that most of the ARGs have high PZI values. As the PZI map has the highest spatial resolution among these three permafrost maps, we further compared our inventoried ARGs with the PZI map.

We randomly selected two subregions "Z1" and "Z3" (see their locations in Fig. 9b) in the western and eastern of the NTS, respectively, to examine the distributions of ARGs in the PZI map. It is evident that most of the MARGs are located above the PZI contour line of 0.8 (Fig. 10a and c). We selected the zone "Z2" (see its location in Fig. 9b) as another example as it contains both the MARG and TARG that have the lowest FLP altitude in their corresponding category. The MARG developing in the narrow valley (location: $84.2957^{\circ} \mathrm{E}, 44.0021^{\circ} \mathrm{N}$; outlined by the red polygon in Fig. 10b) has an FLP altitude of $2575 \mathrm{~m}$. The TARG (location: $84.2883^{\circ} \mathrm{E}, 44.0228^{\circ} \mathrm{N}$; outlined by the blue polygon in Fig. 10b) has an FLP altitude of $2490 \mathrm{~m}$. The PZI values at the front points of these two ARGs are still higher than 0.2.

The PZI value at the FLP of an ARG shows how favorable the lowest altitude that the rock glacier reaches would for permafrost to exist. The statistical distribution of PZI at FLPs shows that most ARGs (73\%) are located in the PZI interval of 0.5 to 0.9 (Fig. 11a). The PZI density peaks at about 0.8 for the MARGs and 0.5 for the TARGs (Fig. 11bc). The PZI density decreases towards the lower PZI values for the MARGs, while it decreases towards both ends of the distribution (Fig. 11c) for the TARGs. This difference in PZI distribution is probably because the TARGs are located at relatively lower altitudes than the MARGs. The PZI values at lower altitudes show a larger variability as the air temperature increases. The mean PZI values at the FLPs are 0.64, 0.67 , and 0.57 for all ARGs, MARGs, and TARGs, respectively, indicating the spatial distribution of the ARGs agrees well with the PZI map.

\section{Conclusions}

In this study, we successfully mapped and inventoried 261 active rock glaciers in the northern Tien Shan of China by combining the use of the SAR interferometry and optical images from Google Earth. Based on the creep boundaries of the active rock glaciers determined by this novel method, we estimated the lower limit of the permafrost presence in the northern Tien Shan. From the inventory and analyses, we draw the following conclusions:
Most of the active rock glaciers in the northern Tien Shan are moraine derived, tongue shaped, and northeast facing. The moraine-derived active rock glaciers are generally longer, steeper, and larger than the talus-derived active rock glaciers. The total area of the active rock glaciers is about $91.5 \mathrm{~km}^{2}$ and moraine-derived ones occupy most of this area $(85 \%)$.

The latitude and longitude locations have a strong influence on the altitude distribution the active rock glaciers. We found the altitudes of active rock glaciers generally increase from west to east and decrease from south to north. We also found distinct altitude distributions of active rock glaciers in the western and eastern parts of the northern Tien Shan (divided by $86^{\circ} \mathrm{E}$ ), probably due to the influence of distinct climates of these two subregions.

We found that the lower limit of permafrost in the eastern part of the northern Tien Shan is higher than in the western part. The lower altitudinal limit for the permafrost distribution throughout the northern Tien Shan is about 2500$2800 \mathrm{~m}$.

The study presented here provides the first comprehensive and modern documentation of the characteristics of the active rock glaciers in the northern Tien Shan of China. It updates the lower limit of permafrost occurrence for this vast area. This inventory offers a baseline dataset for the further investigations on permafrost modeling, slope stability, water resource, etc. The successful application of the proposed method in the northern Tien Shan promises that this method can be used for other high mountains globally, thus helping to close the gaps in our knowledge of rock glaciers worldwide. This new knowledge will be useful to infer alpine permafrost occurrence in high mountains.

Data availability. The locations and characteristic parameters of the 261 inventoried active rock glaciers for downloading and visualizing are available in the Supplement. Both the KMZ file and shapefiles are provided. Alternatively, the data can be downloaded from PANGAEA (doi:10.1594/PANGAEA.874616). 


\section{Appendix A: List of acronyms}

$\begin{array}{ll}\text { ALOS } & \text { Advanced Land Observing Satellite } \\ \text { ARG } & \text { Active rock glacier } \\ \text { CAS } & \text { Chinese Academy of Sciences } \\ \text { FLP } & \text { Front line point } \\ \text { GPS } & \text { Global Positioning System } \\ \text { ILP } & \text { Initial line point } \\ \text { InSAR } & \text { Interferometric synthetic aperture radar } \\ \text { IPA } & \text { International Permafrost Association } \\ \text { MAAT } & \text { Mean annual air temperature } \\ \text { MARG } & \text { Moraine-derived active rock glacier } \\ \text { NCAR } & \text { National Center for Atmospheric Research } \\ \text { NCEP } & \text { National Centers for Environmental Prediction } \\ \text { NTS } & \text { Northern Tien Shan } \\ \text { PALSAR } & \text { Phased Array type L-band Synthetic Aperture Radar } \\ \text { PISR } & \text { Potential income of solar radiation } \\ \text { PZI } & \text { Permafrost Zonation Index } \\ \text { SRTM } & \text { Shuttle Radar Topography Mission } \\ \text { TARG } & \text { Talus-derived active rock glacier }\end{array}$




\section{The Supplement related to this article is available online at doi:10.5194/tc-11-997-2017-supplement.}

Competing interests. The authors declare that they have no conflict of interest.

Acknowledgements. We thank Tobias Bolch, Gengnian Liu, Tazio Strozzi, and the Editor for their constructive and insightful reviews, which have helped to improve the quality of this paper. The ALOS PALSAR data are copyrighted by the Japan Aerospace Exploration Agency and provided by the Alaska Satellite Facility, University of Alaska Fairbanks. The CAS permafrost map is provided by Environmental and Ecological Science Data Center for West China, National Natural Science Foundation of China (http://westdc.westgis.ac.cn). The IPA permafrost map is provided by the Frozen Ground Data Center at the National Snow and Ice Data Center (NSIDC), Boulder, Colorado, USA (http://nsidc.org/data/GGD318/versions/2). The MAAT and permafrost map zonation data are downloaded from http://www.geo.uzh.ch/microsite/cryodata/pf_global/. Some figures in this paper were plotted using the Generic Mapping Tools (Wessel et al., 2013). Work at the Chinese University of Hong Kong was supported by Hong Kong Research Grants Council grants CUHK24300414 and CUHK14300815.

Edited by: T. Zhang

Reviewed by: T. Bolch, G. Liu, and T. Strozzi

\section{References}

Aizen, V. B., Aizen, E. M., and Melack, J. M.: Climate, snow cover, glaciers, and runoff in the Tien Shan, central Asia, J. Am. Water Resour. As., 31, 1113-1129, 1995.

Angillieri, M. Y. E.: A preliminary inventory of rock glaciers at $30^{\circ}$ S latitude, Cordillera Frontal of San Juan, Argentina, Quaternary Int., 195, 151-157, doi:10.1016/j.quaint.2008.06.001, 2009.

Avian, M., Kellerer-Pirklbauer, A., and Bauer, A.: LiDAR for monitoring mass movements in permafrost environments at the cirque Hinteres Langtal, Austria, between 2000 and 2008, Nat. Hazards Earth Syst. Sci., 9, 1087-1094, doi:10.5194/nhess-9-1087-2009, 2009.

Barboux, C., Strozzi, T., Delaloye, R., Wegmüller, U., and Collet, C.: Mapping slope movements in alpine environments using TerraSAR-X interferometric methods, ISPRS J. Photogramm., 109, 178-192, doi:10.1016/j.isprsjprs.2015.09.010, 2015.

Barsch, D.: Rock Glaciers: Indicators for the Present and Former Geoecology in High Mountain Environments, Berlin, Springer, 1996.

Berger, J., Krainer, K., and Mostler, W.: Dynamics of an active rock glacier (Otztal Alps, Austria), Quaternary Res., 62, 233242, doi:10.1016/j.yqres.2004.07.002, 2004.

Berthling, I.: Beyond confusion: rock glaciers as cryoconditioned landforms, Geomorphology, 131, 98-106, doi:10.1016/j.geomorph.2011.05.002, 2011.

Boeckli, L., Brenning, A., Gruber, S., and Noetzli, J.: Permafrost distribution in the European Alps: calculation and evaluation of an index map and summary statistics, The Cryosphere, 6, 807820, doi:10.5194/tc-6-807-2012, 2012.

Bolch, T. and Gorbunov, A. P.: Characteristics and Origin of Rock Glaciers in Northern Tien Shan (Kazakhstan/Kyrgyzstan), Permafrost Periglac., 25, 320-332, 2014.

Bolch, T., Buchroithner, M. F., Kunert, A., Kamp, U.: Automated delineation of debris-covered glaciers based on ASTER data, in: Geoinformation in Europe (Proc. of 27th EARSel Symposium), Bozen, Italy, 403-410, 2007.

Bollmann, E., Girstmair, A., Mitterer, S., Krainer, K., Sailer, R., and Stotter, J.: A rock glacier activity index based on rock glacier thickness changes and displacement rates derived from airborne laser scanning, Permafrost Periglac., 26, 347-359, doi:10.1002/ppp.1852, 2015.

Brenning, A.: Geomorphological, hydrological and climatic significance of rock glaciers in the Andes of Central Chile, Permafrost Periglac., 16, 231-240, doi:10.1002/ppp.528,, 2005.

Brenning, A. and Trombotto, D.: Logistic regression modeling of rock glacier and glacier distribution: Topographic and climatic controls in the semi-arid Andes, Geomorphology, 81, 141-154, doi:10.1016/j.geomorph.2006.04.003, 2006.

Brenning, A., Grasser, M., and Friend, D. A.: Statistical estimation and generalized additive modeling of rock glacier distribution in the San Juan Mountains, Colorado, United States, J. Geophys. Res.-Earth, 112, F02S15, doi:10.1029/2006jf000528, 2007.

Brenning, A., Long, S. L., and Fieguth, P.: Detecting rock glacier flow structures using Gabor filters and IKONOS imagery, Remote Sens. Environ., 125, 227-237, doi:10.1016/j.rse.2012.07.005, 2012.

Brown, J., Ferrians, O., Heginbottom, J. A., and Melnikov, E.: Circum-Arctic Map of Permafrost and Ground-Ice Conditions, USA Natl. Snow Ice Data Center, Boulder, Colorado, 1998.

Clark, D. H., Steig, E. J., Potter Jr., N., and Gillespie, A. R.: Genetic variability of rock glaciers, Geogr. Ann. A, 80A, 175-182, 1998.

Cui, Z. J.: The discovery of the Kunlunshan-type rock glacier and the latest classification of rock glaciers, Chin. Sci. Bull., 810 813, 1984. (in Chinese)

Cui, Z. J. and Zhu, C.: The structure pattern of temperature and mechanism of the rock glaciers in Urumqi River region in Tien Shan, Chinese Sci. Bull., 134-137, 1989 (in Chinese).

Davies, B. J., Glasser, N. F., Carrivick, J. L., Hambrey, M. J., Smellie, J. L., and Nyvlt, D.: Landscape evolution and ice-sheet behaviour in a semi-arid polar environment, Geological Society, London, Special Publications, 381, 353-395, doi:10.1144/Sp381.1, 2013.

Farr, T. G., Rosen, P. A., Caro, E., Crippen, R., and Duren, R.: The Shuttle Radar Topography Mission, Rev. Geophys., 45, RG2004, doi:10.1029/2005RG000183, 2004.

Gorbunov, A. P., Seversky, E. V., Titkov, S. N., Marchenko, S. S., and Popov, M.: Rock glaciers, Zailiysiky Range, Kungei Ranges, Tienshan, Kazakhstan. National Snow and Ice Data Center/World Data Center for Glaciology, Boulder, CO, Digital media, 1998.

Gorbunov, A. P., Marchenko, S. S., and Seversky, E. V.: The thermal environment of blocky materials in the mountains of Central Asia, Permafrost Periglac., 15, 95-98, 2004.

Gorbunov, A. P., Titkov, S. N., and Polyakov, V.: Dynamics of the Rock Glaciers of the Northern Tien Shan and the Djungar Alatau, Kazakhstan, Permafrost Periglac., 3, 29-39, 1992. 
Gruber, S.: Derivation and analysis of a high-resolution estimate of global permafrost zonation, The Cryosphere, 6, 221-233, doi:10.5194/tc-6-221-2012, 2012.

Haeberli, W., Hallet, B., Arenson, L., Elconin, R., Humlum, O., Kääb, A., Kaufmann, V., Ladanyi, B., Matsuoka, N., Springman, S., and Vonder Muhll, D.: Permafrost creep and rock glacier dynamics, Permafrost Periglac., 17, 189-214, doi:10.1002/ppp.561, 2006.

Hanssen, R. F.: Radar interferometry: data interpretation and error analysis, Springer Science \& Business Media, 2001.

Humlum, O.: The climatic significance of rock glaciers, Permafrost Periglac., 9, 375-395, doi:10.1002/(Sici)10991530(199810/12)9:4<375::Aid-Ppp301>3.3.Co;2-S, 1998.

Humlum, O.: The geomorphic significance of rock glaciers: estimates of rock glacier debris volumes and headwall recession rates in West Greenland, Geomorphology, 35, 41-67, doi:10.1016/S0169-555x(00)00022-2, 2000.

Ikeda, A. and Matsuoka, N.: Pebbly versus bouldery rock glaciers: Morphology, structure and processes, Geomorphology, 73, 279296, doi:10.1016/j.geomorph.2005.07.015, 2006.

Janke, J. R.: The occurrence of alpine permafrost in the Front Range of Colorado, Geomorphology, 67, 375-389, doi:10.1016/j.geomorph.2004.11.005, 2005.

Janke, J. R., Bellisario, A. C., and Ferrando, F. A.: Classification of debris-covered glaciers and rock glaciers in the Andes of central Chile, Geomorphology, 241, 98-121, doi:10.1016/j.geomorph.2015.03.034, 2015.

Jin, H. J., Qiu, G. Q., Zhao, L., Wang, S. J., and Zeng, Z. G.: Thermal Regime of Alpline Permafrost in the Upper Reach of Urumqi River, Tian Shan, Journal of Glaciology and Geocryology, 15, 110-114, 1993 (in Chinese).

Kääb, A., Haeberli, W., and Gudmundsson, G. H.: Analysing the creep of mountain permafrost using high precision aerial photogrammetry: 25 years of monitoring Gruben rock glacier, Swiss Alps, Permafrost Periglac., 8, 409-426, 1997.

Kääb, A., Kaufmann, V., Ladstadter, R., and Eiken, T.: Rock glacier dynamics: implications from high-resolution measurements of surface velocity fields, in: Eighth International Conference on Permafrost, 1, 501-506, 2003.

Kenyi, L. W. and Kaufmann, V.: Estimation of rock glacier surface deformation using SAR interferometry data, IEEE T. Geosci. Remote, 41, 1512-1515, doi:10.1109/Tgrs.2003.811996, 2003.

Konrad, S. K., Humphrey, N. F., Steig, E. J., Clark, D. H., Potter, N., and Pfeffer, W. T.: Rock glacier dynamics and paleoclimatic implications, Geology, 27, 1131-1134, doi:10.1130/00917613(1999)027<1131:Rgdapi>2.3.Co;2, 1999

Kumar, L., Skidmore, A. K., and Knowles, E.: Modelling topographic variation in solar radiation in a GIS environment, Int. J. Geogr. Inf. Sci., 11, 475-497, doi:10.1080/136588197242266, 1997.

Lambiel, C. and Delaloye, R.: Contribution of real-time kinematic GPS in the study of creeping mountain permafrost: Examples from the Western Swiss Alps, Permafrost Periglac., 15, 229-241, doi:10.1002/ppp.496, 2004

$\mathrm{Li}, \mathrm{S}$. and Yao, H.: Preliminary study of rock glaciers in the Gongga Mt. Area, Journal of Glaciology and Geocryology, 9, 55-59, 1987 (in Chinese).

Li, Y. A. and Li, Y. K.: Topographic and geometric controls on glacier changes in the central Tien Shan, China, since the Little Ice Age, Ann. Glaciol., 55, 177-186, doi:10.3189/2014AoG66A031, 2014.

Lilleøren, K. S. and Etzelmüller, B.: A Regional inventory of rock glaciers and ice-cored moraines in Norway, Geogr. Ann. A, 93a, 175-191, doi:10.1111/j.1468-0459.2011.00430.x, 2011.

Lilleøren, K. S., Etzelmüller, B., Gartner-Roer, I., Kääb, A., Westermann, S., and Gudmundsson, A.: The distribution, thermal characteristics and dynamics of permafrost in Trollaskagi, Northern Iceland, as inferred from the distribution of rock glaciers and ice-cored moraines, Permafrost Periglac., 24, 322-335, doi:10.1002/ppp.1792, 2013.

Liu, G. N., Xiong, H. G., Cui, Z. J., and Song, C. Q.: The morphological features and environmental condition of rock glaciers in Tianshan mountains, Scientia Geographica Sinica, 15, 226-233, 1995 (in Chinese).

Liu, L., Millar, C. I., Westfall, R. D., and Zebker, H. A.: Surface motion of active rock glaciers in the Sierra Nevada, California, USA: inventory and a case study using InSAR, The Cryosphere, 7, 1109-1119, doi:10.5194/tc-7-1109-2013, 2013.

Lukas, S., Nicholson, L. I., and Humlum, O.: Comment on Lønne and Lysa (2005): "Deglaciation dynamics following the Little Ice Age on Svalbard: Implications for shaping of landscapes at high latitudes", Geomorphology, 84, 145-149, doi:10.1016/j.geomorph.2006.07.003, 2007.

Millar, C. I., Westfall, R. D., Evenden, A., Holmquist, J. G., Schmidt-Gengenbach, J., Franklin, R. S., Nachlinger, J., and Delany, D. L.: Potential climatic refugia in semi-arid, temperate mountains: Plant and arthropod assemblages associated with rock glaciers, talus slopes, and their forefield wetlands, Sierra Nevada, California, USA, Quaternary Int., 387, 106-121, doi:10.1016/j.quaint.2013.11.003, 2015.

Necsoiu, M., Onaca, A., Wigginton, S., and Urdea, P.: Rock glacier dynamics in Southern Carpathian Mountains from highresolution optical and multi-temporal SAR satellite imagery, Remote Sens. Environ., 177, 21-36, doi:10.1016/j.rse.2016.02.025, 2016.

Onaca, A., Ardelean, F., Urdea, P., and Magori, B.: Southern Carpathian rock glaciers: Inventory, distribution and environmental controlling factors, Geomorphology, doi:10.1016/j.geomorph.2016.03.032, in press, 2016.

Qiu, G. Q.: Development condition of alpline permafrost in the Mt. Tianshan, China, Journal of Glaciology and Geocryology, 15, 96-103, 1993 (in Chinese).

Qiu, G. Q., Huang, Y. Z., and Li, Z. F.: Basic Characteristics of permafrost in Tian Shan, China, Proceedings of Second National Conference on Permafrost, Lanzhou, 21-29, 1983 (in Chinese).

Rosen, P. A., Hensley, S., Joughin, I. R., Li, F. K., Madsen, S. N., Rodriguez, E., and Goldstein, R. M.: Synthetic aperture radar interferometry, Proceedings of the IEEE, 88, 333-382, doi:10.1109/5.838084, 2000.

Sattler, K., Anderson, B., Mackintosh, A., Norton, K., and de Róiste, M.: Estimating permafrost distribution in the Maritime Southern Alps, New Zealand, based on climatic conditions at rock glacier sites, Frontiers Earth Sci., 4, 1-17, doi:10.3389/feart.2016.00004, 2016.

Schmid, M.-O., Baral, P., Gruber, S., Shahi, S., Shrestha, T., Stumm, D., and Wester, P.: Assessment of permafrost distribution maps in the Hindu Kush Himalayan region using rock glaciers mapped 
in Google Earth, The Cryosphere, 9, 2089-2099, doi:10.5194/tc9-2089-2015, 2015.

Schoeneich, P., Bodin, X., Echelard, T., Kaufmann, V., KellererPirklbauer, A., Krysiecki, J. M., and Lieb, G. K.: Velocity changes of rock glaciers and induced hazards, Engineering Geology for Society and Territory, Vol 1, Climate Change and Engineering Geology, 1, 223-227, doi:10.1007/978-3-319-093000_42, 2015.

Scotti, R., Brardinoni, F., Alberti, S., Frattini, P., and Crosta, G. B.: A regional inventory of rock glaciers and protalus ramparts in the central Italian Alps, Geomorphology, 186, 136-149, doi:10.1016/j.geomorph.2012.12.028, 2013.

Serrano, E., de Sanjose, J. J., and Gonzalez-Trueba, J. J.: Rock glacier dynamics in marginal periglacial environments, Earth Surf. Proc. Land., 35, 1302-1314, doi:10.1002/esp.1972, 2010.

Shi, Y. F. and Mi, D. S.: Map of Snow, Ice and Frozen Ground in China, SinoMaps Press, Beijing, 1988 (in Chinese).

Shi, Z. W., Xu, J. R., Chen, Z. S., and Li, M. Y.: Analysis on climatic changes under global climatic change: a case study of Tianshan Snow and Avalanche Research Station, J. Mt. Sci., 27, 41-48, 2009 (in Chinese).

Sollid, J. L. and Sørbel, L.: Rock glaciers in Svalbard and Norway, Permafrost Periglac., 3, 215-220, doi:10.1002/ppp.3430030307, 1992.

Sorg, A., Kääb, A., Roesch, A., Bigler, C., and Stoffel, M.: Contrasting responses of Central Asian rock glaciers to global warming, Sci. Rep., 5, 8228, doi:10.1038/srep08228, 2015.

Strozzi, T., Kääb, A., and Frauenfelder, R.: Detecting and quantifying mountain permafrost creep from in situ inventory, space-borne radar interferometry and airborne digital photogrammetry, Int. J. Remote Sens., 25, 2919-2931, doi:10.1080/0143116042000192330, 2004.

Sun, C., LI, C., Chen, Y., Zhang, M., Nie, Z., and Liu, G.: A long term monitoring of frost heaving in periglacial environment in the Tianshan mountains, Journal of Glaciology and Geocryology, 35, 272-279, 2013 (in Chinese).
Visser, V., Langdon, B., Pauchard, A., and Richardson, D. M.: Unlocking the potential of Google Earth as a tool in invasion science, Biol. Invasions, 16, 513-2534, 2014.

Wang, X. W., Liu, G. X., Yu, B., Dai, K. R., Zhang, R., Ma, D. Y., and Li, Z. L.: An integrated method based on DInSAR, MAI and displacement gradient tensor for mapping the 3D coseismic deformation field related to the 2011 Tarlay earthquake (Myanmar), Remote Sens. Environ., 170, 388-404, doi:10.1016/j.rse.2015.09.024, 2015.

Wegmüller, U., Werner, C., and Strozzi, T.: SAR interferometric and differential interferometric processing chain, Int. Geosci. Remote Se., 2, 1106-1108, doi:10.1109/IGARSS.1998.699687, 1998.

Wessel, P., Smith, W. H. F., Scharroo, R., Luis, J. F., and Wobbe, F.: Generic Mapping Tools: improved version released, Eos Trans. AGU, 94, 409-410, 2013.

Wirz, V., Gruber, S., Purves, R. S., Beutel, J., Gärtner-Roer, I., Gubler, S., and Vieli, A.: Short-term velocity variations at three rock glaciers and their relationship with meteorological conditions, Earth Surf. Dynam., 4, 103-123, doi:10.5194/esurf-4-1032016, 2016.

Zhao, L., Liu, G. Y., Jiao, K. Q., Li, R., Qiao, Y. Q., and Chien, L. P.: Variation of the Permafrost in the Headwaters of the Urumqi River in the Tianshan Mountains Since 1991, Journal of Glaciology and Geocryology, 32, 223-230, 2010 (in Chinese).

Zhu, C.: Research on the feature of rock glaciers on the central Tian Shan Mountain, ACTA Geographica Sinica, 47, 233-241, 1992a (in Chinese).

Zhu, C., Cui Z. J., and Yao Z.: Some problems from the slope periglacio-landform on middle Tian Shan Mountain, Mountain Research, 10, 65-64, 1992b (in Chinese). 